\title{
Chapter 7 \\ Adaption and Introduction of German Sewer Inspection Technology in China
}

\author{
Marc Jansen, Jan Echterhoff, Tobias Jöckel, and Sven Sturhann
}

\subsection{Introduction}

In China in particular, cities represent the spatial concentration points of society and are always a mirror image of the macro-social development trend. Often, it is at the urban level that global megatrends firstly reveal their concrete impact on people. Whether it be rapidly increasing population growth, processes of climatic change or enormous economic growth, the consequences are pervasive and always have a profound impact on urban society and, above all, on urban systems. This is clearly evident when looking at the current drainage situation in Chinese cities. While the above-ground infrastructures have been continuously adapted to the everincreasing economic growth in the People's Republic, the expansion and maintenance of the under-ground sewage system has been largely neglected. The consequences are devastating and the pressure to act is indispensable.

The objective of SINO-INSPECTION is to provide an important contribution to the maintenance and improvement of the drainage situation in Chinese cities. This project is realized by developing and demonstrating German sewer inspection technologies, adapting these technologies to Chinese conditions and providing scientific proof of their functional efficiency. The joint project SINO-INSPECTION focuses on the Chinese megalopolis of Jiaxing in the Zhejiang province. The practical activities and scientific verification, as well as the derivation of criteria for sewer condition

M. Jansen $(\varangle) \cdot$ J. Echterhoff

Research Institute for Water and Waste Management at the RWTH Aachen University (FiW) e. V., Aachen, Germany

e-mail: jansen@fiw.rwth-aachen.de

T. Jöckel

JT Elektronik GmbH in Lindau, Lindau, Germany

S. Sturhann

Bluemetric Software GmbH in Griesheim, Griesheim, Germany 
assessment as part of SINO-INSPECTION, were supported by the urban drainage companies in Jiaxing and the Zhejiang University in Hangzhou.

The German project consortium consists of employees of the Research Institute for Water and Waste Management at RWTH Aachen University (FiW), employees of the company JT-elektronik $\mathrm{GmbH}$ and employees of the company bluemetric software GmbH.

\subsection{Stage of Urban Drainage Systems in China}

\subsubsection{Definition of Task}

Floods and odour nuisance due to massive sewer deposits as well as increased waterpolluting overflows in mixed sewer systems in inner-city areas have meanwhile led to increased measures for the operation of sewer networks. This includes an increased systematic cleaning of the sewers. A continuing problem of many Chinese sewer systems and sewage treatment plants is the inflow of extraneous water. The main reason for this is the infiltration of groundwater into the sewers caused by leaking sewers, which leads to a significant dilution of the untreated wastewater. As a consequence of this extraneous water, hydraulically overloaded sewers and wastewater treatment plants are the result and, thus, higher substance pollution of surface waters is caused. Despite the above described obvious operating problems, the conditions of the existing sewers are hardly recorded, so that no targeted countermeasures can be taken. Therefore, an efficient assessment of the condition of a sewer system by means of a sewer inspection must be an important and integral part of sustainable wastewater disposal. In addition to maintaining verification of the sewer function, the inspection and the sewer maintenance based on such an inspection play a further economic role, for example as protection against flooding and consecutive damages. The structural components of the sewer network are municipal capital goods with useful lives of up to 100 years. It is thus important to preserve the substance value of the sewer system for a long time. Accordingly, a long preservation of the substance value of the sewerage system is relevant. The methods of optical inspection by means of TV cameras, which have proven their worth in Germany especially for sewers that are not accessible to the public, cannot simply be used in China. A particular difficulty in the condition assessment of many Chinese sewers is caused by the lack of possibilities to shut off the sewage flow during a TV camera inspection. Under the described boundary conditions in China and the desire there for the simplest possible inspection procedures, innovative inspection systems adapted to the conditions in China are required. The aim of the project described below is to make an important contribution to the maintenance and improvement of the drainage situation in China through the development and demonstration of German sewer inspection technologies, the adaption of the technologies to Chinese conditions and the scientific verification of their functional efficiency. Already existing contacts with the 
Chinese city of Jiaxing, which has as one of the first 16 Chinese sponge cities to have a pilot character, revealed various challenges for the operation and maintenance of the sewage systems.

\subsubsection{Conditions Under Which the Project Was Carried Out}

The city Jiaxing is located in the north of the Chinese province Zhejiang. Jiaxing has about 3.53 million inhabitants (as of 2011) and stretches over a total area of 3,915 $\mathrm{km}^{2}$.

Jiaxing is surrounded by the cities of Suzhou, Shanghai and Hangzhou, each about $100 \mathrm{~km}$ to the north, north-east and south-west, and is thus located in one of the more densely populated regions of the world, the Yangtze Delta region. Jiaxing itself consists of two districts, Nanhu and Xiuzhou, two counties, Jiashan and Haiyan, and three independent cities, Pinghu, Haining and Tongxiang. The morphology of the city can be considered flat, with an average altitude of $3.7 \mathrm{~m}$ above sea level and an average gradient of less than $1 \%$. A large number of standing waters and rivers as well as canals are part of the city of Jiaxing. In China's eastern coastal regions, the groundwater level is on average 1-2 m below ground level and thus usually at the level of the sewer system. This leads to groundwater intrusions in large parts of the sewer system. In Guangzhou, the groundwater inflow into the sewer system is so considerable that some sewage treatment plants dilute the COD inflow to below $100 \mathrm{mg} / \mathrm{l}$. In Zhejiang Province, $24.8 \%$ of all sewage treatment plants ave COD inflow values below $200 \mathrm{mg} / 1$ [11-14].

The climate is characterised by significant variations in precipitation over the course of the year. The summer months from June to August show significantly higher precipitation than the autumn/ winter months from October to December (Fig. 7.1). The annual precipitation is about $1,100 \mathrm{~mm}$. Between the years 2000 and 2012, the lowest-precipitation month recorded just under $40 \mathrm{~mm}$ and the highest-precipitation month an average of just under $170 \mathrm{~mm}$ [9].

The current state of knowledge about the condition and general data of the sewage networks in China is poor and largely incomplete. Apart from overall statistics on the total sewer length in China, more comprehensive data is limited to individual investigations in only a few regions of China. ${ }^{1}$

A sewer system with a total length of $510,000 \mathrm{~km}$ exists throughout China. These consist of $210,000 \mathrm{~km}$ of wastewater sewers, $190,000 \mathrm{~km}$ of stormwater and $110,000 \mathrm{~km}$ of combined sewer system (status 2014, [11-14]). By way of comparison, in 2013 Germany had a total sewer system length of $575,580 \mathrm{~km}$ consisting of $206,234 \mathrm{~km}$ of wastewater sewers, $126,480 \mathrm{~km}$ of stormwater sewers and 242,866 km of combined sewer systems [10].

\footnotetext{
${ }^{1}$ E.g..: Huang, Dong-Bin, et al. "Confronting limitations: new solutions required for urban water management in Kunming City.” Journal of Environmental Management 84.1 (2007): 49-61.
} 


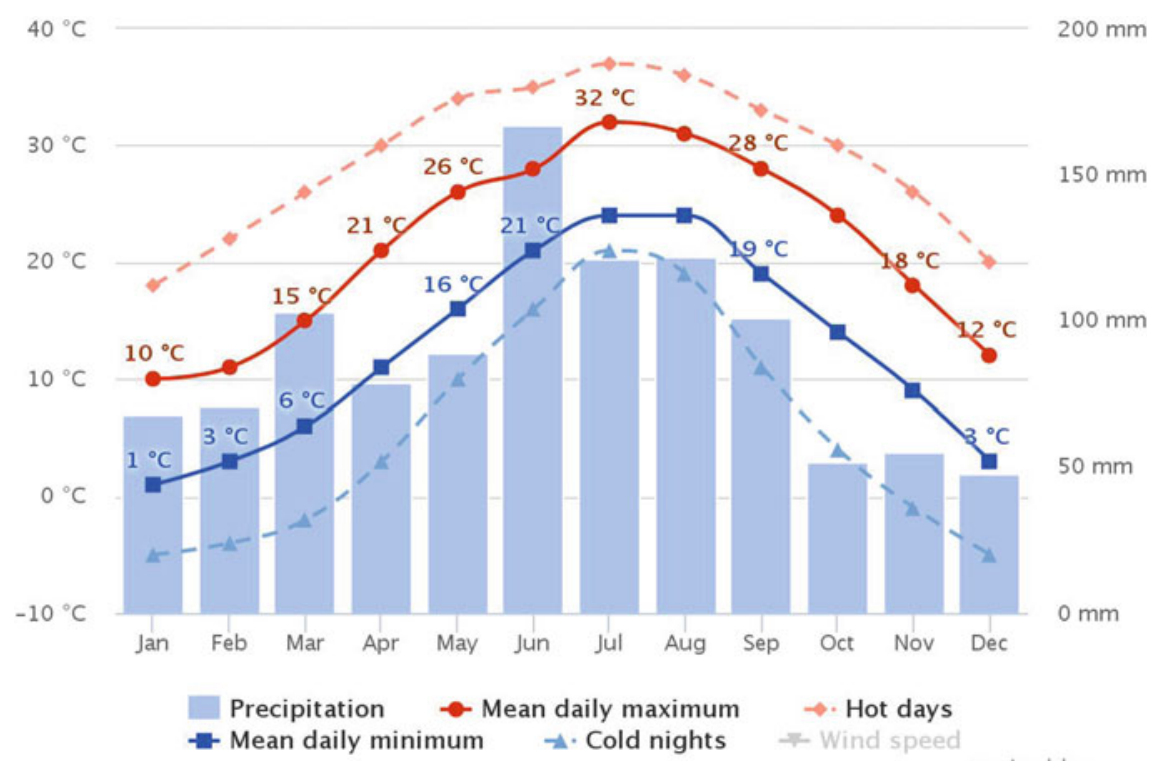

Fig. 7.1 Climate Diagram Jiaxing [9]

Within the Eco-Sponge-City demonstration area in the city of Jiaxing there are $47 \mathrm{~km}$ of wastewater, $140 \mathrm{~km}$ of stormwater and $52 \mathrm{~km}$ of combined sewers this corresponds to about one tenth of the sewer length of the German city of Cologne. Almost nothing is known about the number and regularity of sewer condition. However, these can generally be classified as low. For example, in the city of Chongqing with its 10 million inhabitants, less than $5 \%$ of the entire sewer system has been inspected in the last 10 years [11-14].

The sewer damages leading to extraneous water intrusions are often caused by damage to the sewer pipe itself, leaks in the couplings or coupling offset, subsidence of individual sewer sections due to inadequate sewer bedding, or faulty connections in the separation system. These sewer damages not only lead to constructional risks within the road area and allow for contamination of the soil with wastewater, but also exert a considerable influence on the treatment performance of the connected wastewater treatment plants. The significantly increased water volume generates a hydraulic surplus resp. overloading of the wastewater treatment plants, so that the wastewater loads are no longer sufficiently reduced. 


\subsubsection{Present State of Science and Technology}

\subsubsection{Legal Situation}

\section{Germany}

In Germany, there are a large number of different laws, regulations and standards which prescribe a certain course of action, specify a construction or operating method or serve as a guideline without direct legal binding. In the first place in the hierarchy are legal obligations as a restriction and specification for the construction and operation of drainage systems. These must be fulfilled in order to achieve legal compliance. In addition to the applicable laws, standards also have a significant influence on the construction and operation of drainage systems. Standards, according to the German Institute for Standardization (DIN), or their European (CEN) and international (ISO) pendants, do not, however, have any obligation to be fulfilled. They serve as voluntary guidelines for orientation to the current state of technology, with the exception of explicit regulations for compliance with laws or contracts (German Institute for Standardization 2017).

Legally, a drainage system is governed by the Water Resources Act (WRA) of 2009. Chapter 3, Sect. 2, §54-§ 61 regulates the legal framework for handling wastewater.

$\S 60$, Sect. 7.1 states:

"Abwasseranlagen sind so zu errichten, zu betreiben und zu unterhalten, dass die Anforderungen an die Abwasserbeseitigung eingehalten werden. Im Übrigen müssen Abwasserbehandlungsanlagen [...] nach dem Stand der Technik, andere Abwasseranlagen nach den allgemein anerkannten Regeln der Technik errichtet, betrieben und unterhalten werden." (Wastewater systems must be constructed as well as operated and maintained in such a way that the requirements for wastewater disposal are met. Furthermore, wastewater treatment plants [...] must be constructed, operated and maintained in accordance with the state of the art, other wastewater plants in accordance with the generally recognised rules of technology.)

This is considered the basis for German regulations and standards applied in practice, which, as the current state of technology, are available uniformly throughout Germany as guidelines for compliance with this law. Although their application does not offer any legal guaranty of correctness of the construction and operation of drainage systems, they can help in the event of possible liability, as they make it easier to prove duly behaviour [1].

On federal level, wastewater disposal is covered by the Water Resources Act, as described above. Furthermore, $§ 57$ states:

\footnotetext{
“Abwasser ist von den juristischen Personen des öffentlichen Rechts zu beseitigen, die nach Landesrecht hierzu verpflichtet sind (Abwasserbeseitigungspflichtige). Die Länder können bestimmen, unter welchen Voraussetzungen die Abwasserbeseitigung anderen als den in Satz 1 genannten Abwasserbeseitigungspflichtigen obliegt. Die zur Abwasserbeseitigung Verpflichteten können sich zur Erfüllung ihrer Pflichten Dritter bedienen. " (Wastewater is to be disposed of by corporate bodies under public law, which are obliged to do so under federal state law (wastewater disposal obligors). The states can determine the conditions
} 
under which wastewater disposal resides with persons other than the wastewater disposal obligors mentioned in sentence 1. Persons obliged to dispose of wastewater water may use third parties to fulfil their obligations.)

The responsibility for wastewater disposal is thus transferred to the municipalities or local authorities, with the addition that the state government also has a say. In Germany, this is achieved by means of various wastewater regulations of the state governments. It is also possible for several municipalities to transfer their duty to private service companies. These are often special-law wastewater associations that act as public-law institutions and remain as instruments of the municipalities [7].

The public sewage system, as a pure infrastructure, is thus owned by the municipalities (wastewater disposal obligors). They also take care of its structural and operational condition. Consequently, sewer construction, cleaning and monitoring as well as further steps are the responsibility of the municipalities. These appoint private, certified service providers for a sewer inspection. Larger municipalities usually have their own cleaning and inspection team.

In Europe, the DIN EN 13,508-2 for the assessment and monitoring of drainage systems exists for "the inspection and assessment of drainage systems outside of buildings part 2: Coding system for optical inspection", which is illustrated with the leaflet DWA M 149-2 of the same name by the DWA and supplements the European standard with additional specifications practiced in Germany. The two standards define a coding system for the description of observations made during an optical inspection inside sewers, manholes and inspection openings. In addition, Germany has the leaflet DWA-M 149-5 "Condition assessment and evaluation of drainage systems outside of buildings part 5: Optical inspection", which gives recommendations and assistance for the solution of technical and operational problems as well as for quality management. The aim is to ensure a qualified recording of the actual condition of the drainage systems. The process of optical inspection thus consists of the following sub-steps:

1. work preparation

2. image recording

3. image evaluation with condition description

4. documentation.

\section{China}

While a uniform Europe-wide standard exists with the realization of DIN EN 13,5082 in Germany, in China there are various regional specifications for the assessment of the condition of drainage systems. These partly result from the fact that the official responsibility for water supply and wastewater disposal was previously not clearly regulated. This resulted in conflicts of interest regarding water use and the protection of soil and water to the disadvantage of the expansion of drainage facilities.

Since the reform from 2003 to 2007, the assessment of the condition of drainage systems has been the responsibility of the cities resp. the corresponding department for water management. 


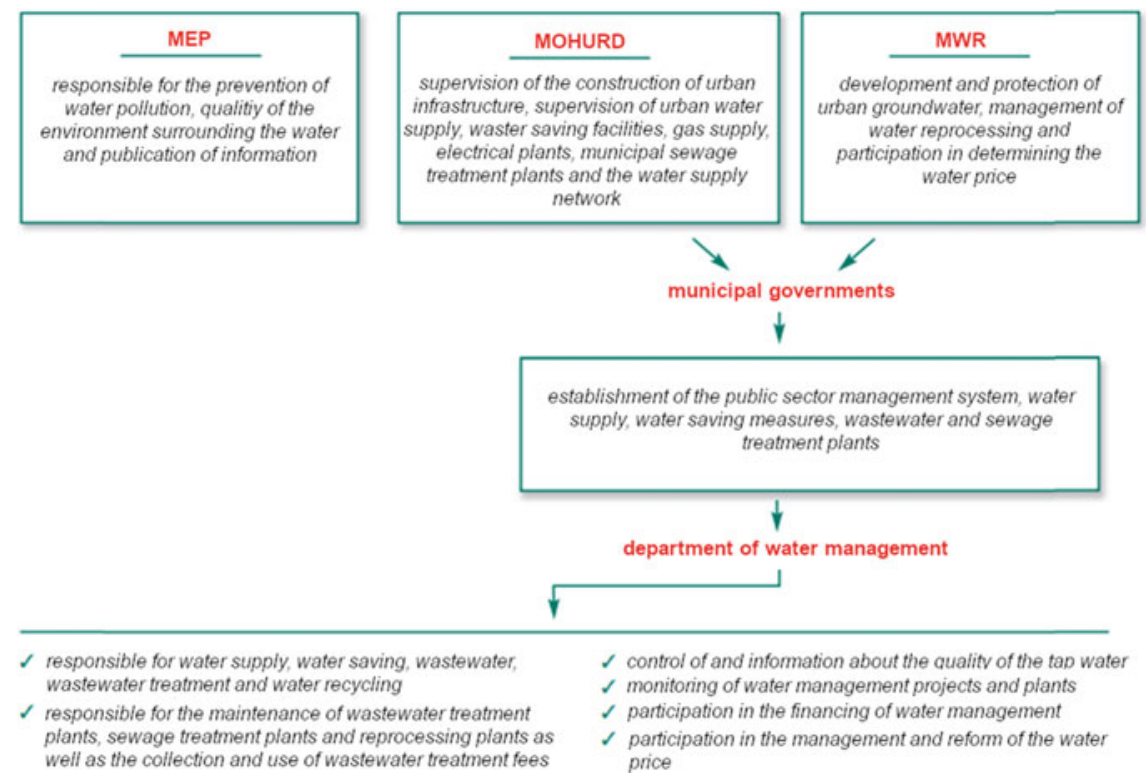

Fig. 7.2 Management of urban water management in China according to Xinjiang conservation fund (2008)

The influences and responsibilities are shown in Fig. 7.2. This reform introduced the concept of "water management" for the first time. It combines traditional water management with water supply and wastewater disposal resp. treatment in sustainable use.

The three most important ministries responsible for monitoring the Water Management Department are the "Ministry of Housing and Urban-Rural Development" (MOHURD), the "Ministry of Environmental Protection" (MEP) and the "Ministry of Water Resources" (MWR).

As can be seen in Fig. 7.2, the drainage systems are the property of the cities, and their construction is subject to or supervised by the MOHURD. Maintenance such as sewer cleaning assessment and monitoring is the responsibility of the Department of Water Management of the city governments. The private companies are responsible for the operation of the water supply and drainage.

Due to this responsibility situation, there are currently many different sets of regulations in the various cities and company structures, which apply to the assessment of sewer condition and all further steps. In the greater Shanghai area and in the neighbouring Zhejiang province, the Chinese standard CJJ 181-2012 - "Recording and technical data of the evaluation of urban sewage systems" is common. 


\subsubsection{Recording of Sewer Condition - Hardware}

The standard for the recording and assessment of the condition of drainage systems is optical inspection. This procedure generally distinguishes between direct optical inspection and indirect optical inspection.

A direct optical inspection is the inspection of manholes and accessible sewers by walking through the canal/ sewer, whereas the indirect inspection is an optical inspection by camera.

Depending on the methods used, optical inspection can essentially be used to detect and qualitatively assess clearly visible damage such as cracks, shattering, pipe breakage and collapse. Leaks without visible damage can only be detected by means of infiltrations, increased water flow at times when the volume of wastewater is normally low or when the accumulation of sediment is increased. In all other cases, leaks can only be detected by means of leak tests (cf. Annex A-2.5).

In Germany, the condition recording is preceded by a cleaning process, which has an additional positive effect. Cleaning the sewers removes blockages, which reduces sewer flooding and odour emissions (LfU 2016). Consequently, the condition recording also has a practical aspect that benefits the residents. Furthermore, there is a risk of the formation of explosive mixtures or harmful gases in the sewer system, especially in the manholes, due to putrefactive processes [2]. Regular sewer cleaning and condition assessment also limit this gas formation, as deposits and limitations of the hydraulic capacity can be eliminated at an early stage.

\section{Innovative Procedures for Sewer Inspection and Sewer Assessment}

The techniques used in Germany for optical assessment are based on a variety of camera systems. They are either carried through the sewer by wheel-based inspection crawler cameras using a flushing nozzle or they are manually pushed through the sewer. In the following two selected systems are presented, which offer the possibility to be adapted to the requirements of the Chinese sewers.

\section{Sewer Inspection Using Electronic Sewer Mirrors (FastPicture Method)}

The electronic sewer mirror (Fig. 7.3) is a camera system with integrated lighting equipment.

The example of the FastPicture system from JT-Elektronik is a Full-HD camera (resolution $1920 \times 1080$, zoom $360 \times(30 \times$ optical/12 $\times$ digital $)$ ). By using highly efficient LEDs, an illumination of over $100 \mathrm{~m}$ is possible.

This camera system is attached to a telescopic rod, which ensures variable use with differing shaft depths. The system is installed directly at the entrance of the manhole, which means that it is no longer necessary for inspection personnel to enter the shaft.

The installation itself proves to be very simple, which results in a quick status check. The camera/ lighting unit itself has an electronic tilt mechanism, which allows the technician to manually align the camera to the optimal position for image. For the recording, the camera is zoomed into the position to be examined. The recording itself can be saved either as a photo or a video. In addition, the technician can make 


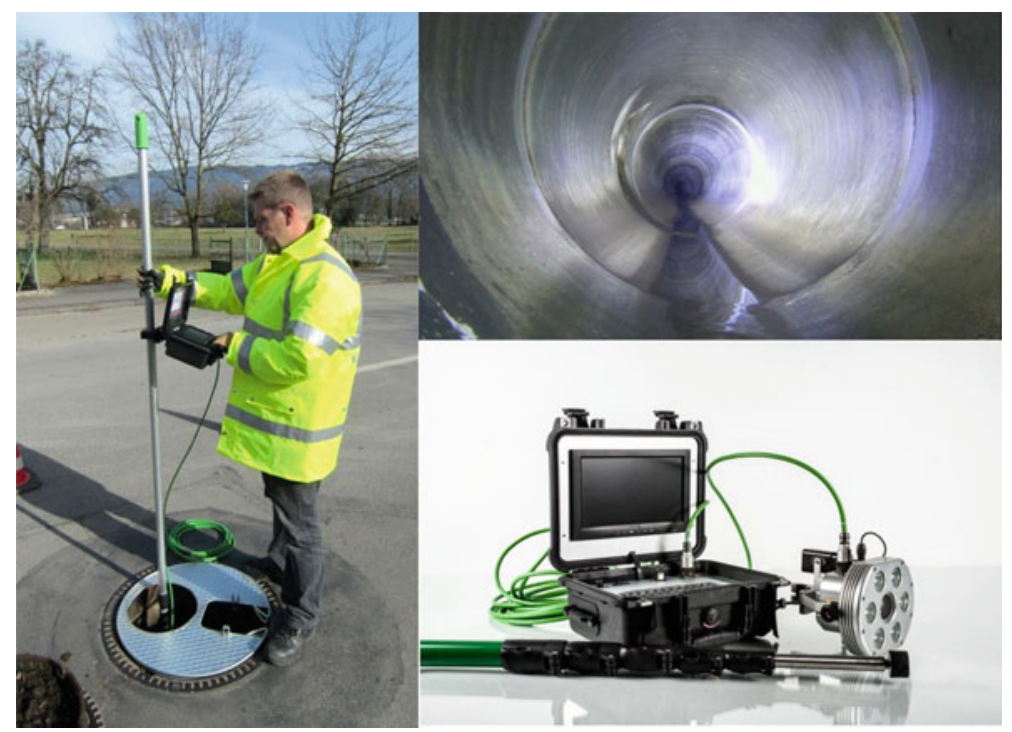

Fig. 7.3 FastPicture system by JT-elektronik GmbH (JT Elektronik)

real-time assessments via a high-resolution monitor to manually change the setting if necessary.

The use of an electronic sewer mirror does not require any prior cleaning of the area to be examined. The electronic sewer mirror can be used up to a filling level of approx. $20 \%$.

A disadvantage of this inspection method is that damage in the sewer can only be viewed from a distance. It is not possible to make a recording for the purpose of qualitative damage assessment from a direct proximity using an electronic sewer mirror, apart from damage to the manhole itself.

Furthermore, it is possible as part of the inspection of a section of a sewer to visually inspect the condition of the shaft when lowering and raising the equipment.

In combination with inspection devices that have to be guided through the sewer, the sewer mirror enables a quick pre-assessment. Obstacles in the sewer that the inspection device cannot overcome or damage can be detected before driving through it.

\section{Sewer Assessment Using Satellite Camera (SKI Method)}

Sewer condition assessment by means of a satellite camera combines sewer cleaning through a high-pressure nozzle with optical recording of the sewer condition.

A camera is installed at the head of this maintenance and inspection device next to the individual cleaning nozzles that exit to the rear (Fig. 7.4). The camera is either fixed (satellite camera - JT-Elektronik, Lindau) or swivelling (Lindauer bulb JT-Elektronik, Lindau). 

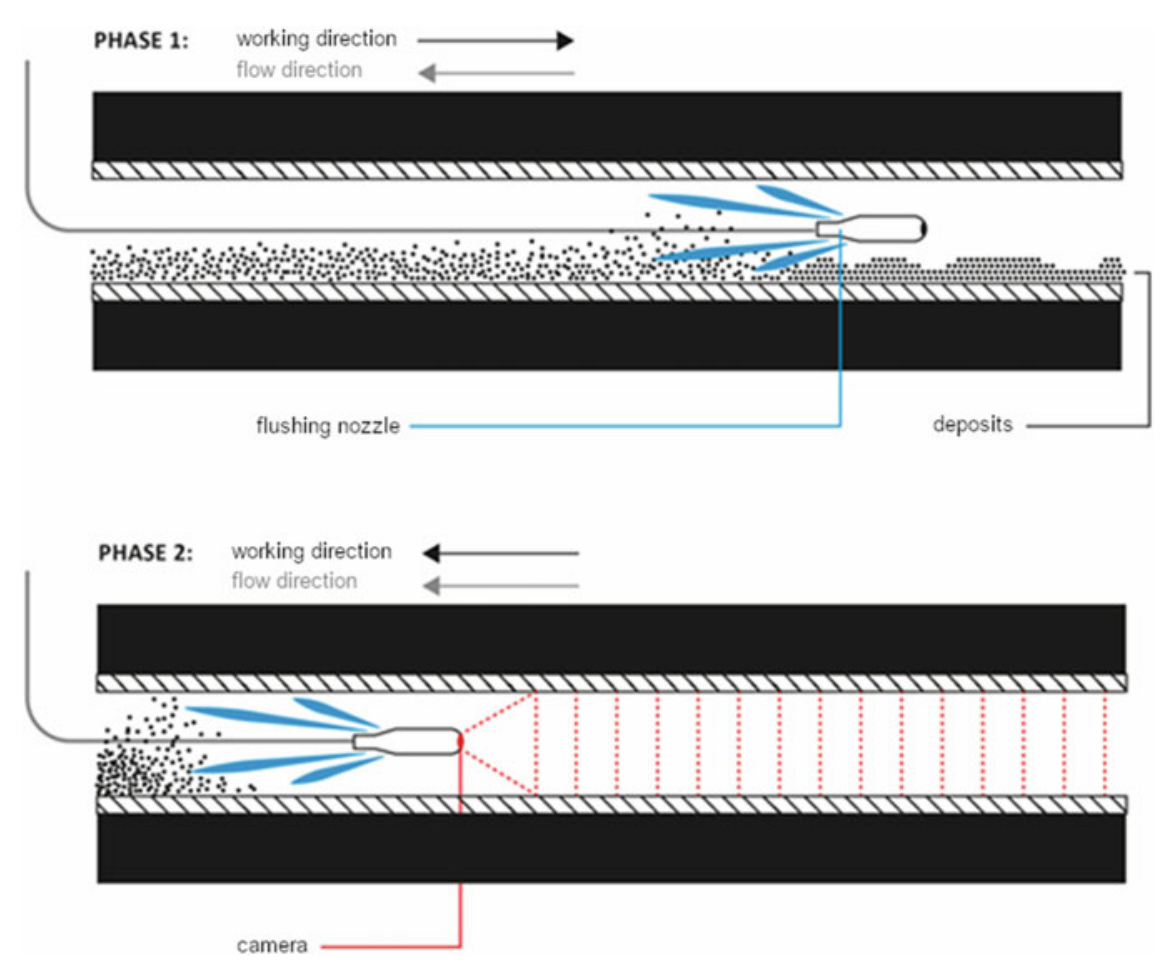

Fig. 7.4 Schematic of High-Pressure cleaning method (FiW)

In Germany, this widely used process for sewer cleaning is called high pressure flushing (HD) process.

After installation in the entry shaft, the nozzle head, together with the hose, is pressed by water jets escaping to the rear against the flow direction from the entry shaft to the target shaft. The water pressure at the cleaning nozzles is usually between 80 and 100 bar. In this phase existing deposits in the sewer are loosened. As soon as the target shaft is reached, the hose is slowly retracted. Due to the water that continues to flow out of the cleaning nozzles, the deposits are also washed away and the driven-on area is cleaned. In this phase the camera inspection is carried out. As a result, the cleaning of the sewer can be inspected as well as the condition of the sewer. A usable camera inspection can be realized at a filling level of up to 20 percent. The satellite cameras from JT-Elektronik are suitable for sewer diameters from DN 70 to DN 300. In addition, there are also cleaning nozzles that can be used up to a diameter of DN 1200. Another argument in favour of this method is that it can be installed easily and quickly with relatively little personnel resources ( 2 persons). It is not applicable for thicker deposits, as the cleaning performance is not realizable. Furthermore, it is not advisable to use the HD method for already damaged sewers, as there is a high risk that the damage will be increased by the high pressure of the 
water jet. Care must also be taken in the area of the sewer sleeves so that they are not damaged.

The stresses on the pipe surface are dependent on:

- The water pressure at the cleaning nozzle,

- The amount of water,

- The distance of the cleaning nozzle to the pipe wall,

- The number, the cross-section and the outlet angle of the cleaning nozzles.

\section{China}

In China, a sewer inspection cannot be carried out by a complete closure of one or more sewerage sections. As opposed to Germany, the sewer infrastructure is not developed to such an extent that the wastewater can be diverted without problems. This is partly due to the infrastructure itself, and partly to the high level in the sewer network caused by groundwater intrusion. As soon as an area is completely blocked off for inspection purposes, there is a risk of flooding in the areas in front of the blocked-off sewer area within a short time.

At the moment, four different methods are applied in China in the field of sewer inspection:

CCTV-method,

Damage detection by sonar,

GPR-method and.

Periscope procedure.

The most widely used procedure is the CCTV (Closed Circuit Television) method. This procedure corresponds to the sewer robots known here in Germany with integrated rotary head camera. Using this procedure, the crawler equipped with a camera travels over the area to be viewed. Prerequisite for the use of this technique is a low filling level and a prior cleaning of the section to be examined, which cannot be realized optimally in China due to the above mentioned reasons.

Another inspection method used is the detection of damaged areas using sonar. Here a sonar probe is installed onto a floating body which moves through the pipe at high filling levels and inspects the sewer pipe by means of sonar. When evaluating the sonar recordings, it is difficult to distinguish damage to the bottom of the sewer from deposits. There is a great risk of misinterpretation and thus wrong conclusions during sewer inspection.

The GPR method (Ground Penetrating Radar) works in a similar fashion to the sonar inspection method. Only the operating principle of this method is not based on sonar technology, but on the use of radar antennas. Similar to the CCTV method, the GPR method is only feasible at low levels, as too high a water content complicates a radar operation and falsifies the radargrams. Accordingly, the GPR method is only conditionally practicable in China.

Recently, inspection trials have been running in China with a periscope method, which corresponds to the electrical sewer mirroring widely used in Germany. In Germany, however, this method is only used for first sighting and remote sensing. A 
high quality inspection and exact damage detection, similar to CCTV inspection, is not possible solely with the sewer mirror.

\section{Instructions for Direct Inspection \\ Germany}

With direct inspection, the actual structural condition is assessed by the inspector by means of a local inspection of the sewer system. The inspector enters the sewer system via the manhole and documents the findings and their quantification. A recording in the form of photography and video technology is planned to enable further work steps. According to the German/European standard DIN EN 752:2008-04, direct optical inspection is to be avoided for occupational safety reasons. However, according DIN EN 13,508-01 2013 reads as follows:

"Should it not be possible to obtain sufficient information through indirect inspections, a direct inspection (e. g. walk-through sewer) may be carried out. Requirements concerning the circumstances allowing for direct inspection shall be taken from national rules or obtained from the competent body“.

According to the European standard and the German DWA instruction leaflet, the direct inspection must be carried out by a team of at least two persons. After the sewer has been measured "clear" indicating absence of contamination, i. e. an atmosphere in the sewer which is not dangerous for humans (measurement of gas concentrations such as hydrogen sulphide, carbon dioxide etc.) has been checked, the first inspector enters the section of sewer. This first inspector is equipped with explosion-protected measuring equipment and a portable sewer camera that transmits recordings in real time to the second inspector in the recording vehicle and permits storage of the recorded data. The second inspector evaluates the measurement results in the recording van and gives further instructions to the colleague inspecting the sewer. A radio connection between the two persons is also mandatory. This ensures fast communication and thus work safety, as any emergencies can be communicated quickly [5]. According to the European standard DIN EN 13,50801 2013, a minimum diameter of the sewer of DN 1200 must be given for direct inspection. Moreover, it must be free of wastewater flow during the inspection.

\section{China}

In accordance with the Chinese safety standard for the operation of electrical equipment in potentially explosive atmospheres according to GB 3868-1983, a direct inspection must also be carried out by at least 2 persons. Furthermore, the Chinese CJJ 181-2012 standard specifies four criteria for a direct inspection by an inspector. These are:

- a minimum sewer diameter of $0.8 \mathrm{~m}$,

- a flow velocity of not more than $0.5 \mathrm{~m} / \mathrm{s}$,

- a water depth of not more than $0.5 \mathrm{~m}$ and

- a filling level of less than $50 \%$ as regards the cross section. 
In order to detect damages to drainage systems at an early stage, the sewer network operator in Germany usually carries out a condition assessment every 10 years, and even more frequently in ground water protection areas. Furthermore, visual inspections are recommended when acceptance testing of sewer construction and rehabilitation measures are carried out, and also before the warranty period for new construction or rehabilitation measures expires. The results of the recording of conditions are documented in the sewer cadastral. In the case of sewers that have been repeatedly inspected, a recommendation is made to also retain earlier inspection results (Bavarian State Office for the Environment 2010). Due to the status of German standards and the fact that instructions are not legally binding, the aforementioned time intervals of the condition assessment are not considered legally binding either. Therefore, a sewer operator can decide at his own discretion on the frequency of the condition assessment. Basically, a distinction can be made between three procedures. Concerning the fire brigade method, incidents are eliminated with the help of emergency task forces, who are sent to the incidents in order to repair them without regular inspection beforehand. The preventive strategy is characterised by fixed intervals for the inspection, maintenance and rehabilitation of a sewer section. The last and most frequently chosen option is the inspection strategy based on requirements. With this strategy, maintenance and rehabilitation are carried out on the basis of the evaluated findings according to a rehabilitation plan (Pinnekamp 2014).

The Chinese regulation CJJ 181-2012 specifies an interval of five to ten years for an inspection period. However, the interval varies if a structural or functional defect was detected during a previous inspection, which requires a more frequent inspection (up to 1-2 years). Other reasons for reducing the frequency of inspections are:

- sewers placed in specific soils (eroded soil, flowing sand, etc.),

- sewers older than 30 years,

- sewers which are in poor structural condition,

- infrastructurally important sewers and

- sewers with specific requirements.

Due to the legally binding situation of the Chinese regulatory framework, an exact time frame for the condition assessment can be specified here (CJJ 181-2012, 2012).

\section{Instructions for Indirect Inspection Germany}

Indirect inspection is the assessment of the current condition of sewerages by means of an indirect visual inspection, using remote-controlled sewer inspection techniques. In Germany, the instruction sheet DWA-M 149-5 (according to DIN EN 13,508-01 and DIN EN 13,508-02) specifies the field of application for indirect inspections with a nominal diameter for pipes of DN 100 to 1200 (100 - $1200 \mathrm{~mm})$. The equipment of an indirect inspection comprises the following main components: camera system, drive unit, power supply and data transmission as well as the control unit. According to DWA-M 149-5, the camera systems should be equipped with an optical zoom, autofocus and equipment to ensure an upright image. In addition, functions for quantitative condition assessment or position determination are possible, including 
localisation sensors and functions for damage measurement, e.g. by laser measurement. Halogen lamps or light emitting diodes are used to illuminate the inspection area. Controllable crawler vehicles can be used as from a nominal sewer diameter of DN 100. Adaptation to larger nominal widths is achieved by mechanically or electrically operated height-adjustable units or different wheel sizes. If the use of mobile camera robots is not possible, there is the possibility of a drive by sliding rods or flushing nozzles. The energy supply of the camera as well as the data transmission are realised via a special cable on a motor-driven cable winch, which is also used for length measurement. The control unit is the interface between camera vehicle and inspector. The inspector can use it to operate the sewer camera and view and record the video material on a screen. The evaluation of the documented recordings is software-supported using a coding system [5].

\section{China}

The technical requirements for indirect inspection are described in the Chinese regulations CJJ 181-2012 much like the German regulations. The CCTV contains technically similar main components as those described in the German regulations. It is a mobile crawler equipped with a camera and measuring technology, which captures the surface of the sewer by video technology. The evaluation of the recordings is done by the inspectors in a camera car, who record the condition of the drainage system under consideration of a coding system. The regulations describe a nominal width of at least DN 100 for CCTV inspection. According to the Chinese regulations, the wheels of the crawler must be exchangeable and adjustable in height. Furthermore, the camera should have a lens that can be moved in all directions as well as a zoom function and autofocus. On the monitor of the inspector the date, time and position parameters of the inspection must be made available. A freely adjustable height adjustment of the camera is also required.

\section{Sewer Cleaning Germany}

According to DWA-M-149-5, inspections which fulfil the purpose of assessing the structural condition of an object require a complete and comprehensive cleaning of the object to be inspected in a temporal context to the inspection itself. The temporal connection must be adapted to the operating situation to such an extent that renewed pollution cannot occur. The instruction sheet therefore specifies a lead time for cleaning of $48 \mathrm{~h}$ [5]. High-pressure cleaning as well as cleaning procedures adapted to the degree of soiling are mentioned as cleaning procedures. In highpressure cleaning, a flushing nozzle is moved through the sewer section. This nozzle conveys the impurities and deposits by water pressure in the direction of the shaft, from where they are removed by means of a suction instrument. According to DWAM-149-5, inspections which fulfil the purpose of assessing the structural condition of an object require a complete and comprehensive cleaning of the object to be inspected in a temporal context to the inspection itself. The temporal connection must be adapted to the operating situation to such an extent that renewed pollution cannot occur. The instruction sheet therefore specifies a lead for cleaning of $48 \mathrm{~h}$ 
[5]. High-pressure cleaning as well as cleaning procedures adapted to the degree of soiling are mentioned as cleaning procedures.

The intensity of the flushing nozzle should be selected so that the sewer section is free of all detachable pollutions and deposits and a full inspection of the sewer wall is possible. The intensity results from the number and size of the flushing nozzles mounted in the nozzle head, which can be optionally mounted in such a way that they can bring a lot of intensity and cleaning power for all areas of the sewer walls. A lower intensity of the flushing nozzle is required, for example, in sewer systems where damage is known or suspected due to obvious circumstances [5]. For an optimal investigation and assessment of a sewerage, attention should be paid to well-trained and experienced cleaning personnel (Vogel 2007). According to DWA-M 149-5, suitable cleaning instruments should be available, even during the inspection, in order to be able to clean the sewer if necessary [5].

\section{China}

The basic principle of sewer cleaning carried out in China is similar to that of German sewer cleaning. In China, this cleaning step is also preceded by the actual inspection in order to be able to better assess the condition of the sewer. Similar to Germany, there are also different cleaning nozzles in China, which can also be varied in cleaning performance by changing the nozzles. Unlike in Germany however the loose deposits are not sucked off at the next manhole, but are dragged along further. In addition, the flushing vehicles and the installed pumps cannot be compared with those used in Germany. There is a clear difference here, if only in terms of the technical equipment and the cleaning performance to be achieved.

A further problem in China is the lack of staff training. Usually the staff is not aware of the sense and purpose of sewer cleaning and therefore there is a lack of awareness for high quality work.

\subsubsection{Coding and Classification of Condition Recording}

An important tool for managing data of drainage systems is the classification and coding of damages and structural elements. Coding is a system that reduces and standardises the complex information of sewer condition recording to a few pieces of data. This enables expert persons to gain a quick and objective insight into the condition assessment.

\section{Germany}

In Germany, DIN EN 13,508-02 and DWA-M 149-2 deal with, among other things, the standardised coding of the sewer condition assessment. First of all, the main code describes the findings made during the status recording. The main codes are divided into those for structure, operation, inventory and other categories. Several main codes can be applied to one element in the drainage system. As an example, a lateral house connection in sewerage section is marked with a structural main code "BCA" and its faulty connection entering the sewer with a code for evaluation of the 
Table 7.1 Example for coding in Germany (cf. [3])

\begin{tabular}{|c|c|c|c|c|c|c|c|c|c|c|c|c|}
\hline \multirow[t]{2}{*}{$\begin{array}{c}\text { Lonotudinal } \\
\text { postition }\end{array}$} & \multirow{2}{*}{ 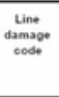 } & \multirow[t]{2}{*}{ Main coste } & \multicolumn{2}{|c|}{ Charactitizason } & \multicolumn{2}{|c|}{ Quantitestion } & \multicolumn{2}{|c|}{$\begin{array}{c}\text { Losastion on the } \\
\text { perimetert }\end{array}$} & \multirow[t]{2}{*}{ connetetion } & \multirow[t]{2}{*}{$\begin{array}{l}\text { Phototo. } \\
\text { retterenee }\end{array}$} & \multirow{2}{*}{$\begin{array}{l}\text { visteo } \\
\text { reterences }\end{array}$} & \multirow[t]{2}{*}{ Annotatens } \\
\hline & & & 1 & 2 & 1 & 2 & 1 & 2 & & & & \\
\hline 16,5 & & $\mathrm{BCA}$ & $\bar{E}$ & A & 100 & & 9 & & & & 00.12 .20 & \\
\hline 16.5 & & BAG & & & 50 & & 9 & & & & $00: 12: 20$ & \\
\hline
\end{tabular}

situation "BAG". Both main codes thus refer to the same event but describe different findings. (The exact origin of the main code can be found in DIN EN 13,508-02 and DWA-M 149-2).

Further coding is added to characterise the finding. The characterisation consists of none, one or at most two details which explain the finding in detail. In the present case seen in Table 7.1, the characterisation 1 with the letter E describes the type of connection. Therefore this is a structural characterisation of the finding. The second characterisation, marked with the letter A, gives the additional information that a blocked connection is involved. As a further coding, details quantifying the finding are added. Quantification for structural recordings includes, for example, the diameter of connections and for stocktaking surveys, for example, the reduction of the cross section of the sewer. Further information in the coding system are positional data. To determine the location of the detection, these are specified in metres [m] in the longitudinal direction of the distance from the reference point of the inspection. DIN EN 13,508-02 specifies various procedures for selecting the reference point. The most frequently selected reference point is the inner wall of the initial node, such as shaft, inspection opening, outlet, etc., in which the position of the sewer to be inspected is integrated. As a further description of the position of the finding, the positioning on the section wall, using the dial reference (time), is determined. This in turn is determined by the angle, which results from the centre of the cross section between the finding and the sewer vertex [3].

\section{China}

In China, the CJJ-181 standard is concerned with the uniform coding of channel status recording. If the standard is complied with, the basic information is first of all uniformly recorded as master data. This data can be adopted from the system and adapted if the sewer database is properly managed. Basic information on the examined sewerage system (number, age, material, nominal width, length, initial depth, final depth), the selected inspection procedure as well as its realisation (date, time, inspection direction) and the operators involved in a sewer inspection (name of the inspector, the supervisor and the inspector) are given.

In the CJJ-181 standard, a damage code describes the finding that was made during the condition assessment. The damage codes are divided into structural and functional damage parameters. Structural damage is damage to the structure of the sewer such as breakages, cracks, fissures or deformations. Functional damages primarily influence the function of the sewerage through external factors such as deposits or root ingrowing. After a definition of the damage, the damage is classified into 4 categories. The categorisation is based on quantifiable arguments. Each damage category 
is assigned points per damage, which serve the subsequent condition assessment of the drainage system (Table 7.2).

In addition to the damage codes, the Chinese standard specifies codes for the recording of so-called operational status information, which describe the start and end position of the damage or which give an abort of the inspection with a corresponding reason (e.g. camera under water). The code of a damage to the pipe system is assigned to the start position if it is longer than $1 \mathrm{~m}$ and to the end position if the length of the damage is less than $1 \mathrm{~m}$. There are also codes for special constructions and secondary installations such as inverted siphons or shafts hidden on the surface.

Table 7.2 Examples to describe the structural and functional damage of a drainage system according to the Chinese standard CJJ-181

\begin{tabular}{|c|c|c|c|c|c|}
\hline $\begin{array}{l}\text { Type of Damage } \\
\text { (structural) }\end{array}$ & $\begin{array}{l}\text { Damage } \\
\text { Code }\end{array}$ & Definition & $\begin{array}{l}\text { Category } \\
\text { of } \\
\text { Damage }\end{array}$ & Description of Categories & $\begin{array}{l}\text { Points } \\
\text { of }\end{array}$ \\
\hline & & & & & Damage \\
\hline \multirow{4}{*}{$\begin{array}{l}\text { 变形 } \\
\text { Bian Xing }\end{array}$} & \multirow{4}{*}{$B X$} & \multirow{4}{*}{$\begin{array}{l}\text { The sewer is } \\
\text { deformed by } \\
\text { external } \\
\text { force }\end{array}$} & 1 & $\begin{array}{l}\text { The deformation is less than } 5 \% \text { of the } \\
\text { pipe diameter. }\end{array}$ & 1 \\
\hline & & & 2 & $\begin{array}{l}\text { The deformation is } 5 \text { to } 15 \% \text { of the pipe } \\
\text { diameter. }\end{array}$ & 2 \\
\hline & & & 3 & $\begin{array}{l}\text { The deformation is } 15 \text { to } 25 \% \text { of the } \\
\text { pipe diameter. }\end{array}$ & 5 \\
\hline & & & 4 & $\begin{array}{l}\text { The deformation is more than } 25 \% \text { of } \\
\text { the pipe diameter. }\end{array}$ & 10 \\
\hline $\begin{array}{l}\text { Type of Damage } \\
\text { (functional) }\end{array}$ & $\begin{array}{l}\text { Damage } \\
\text { Code }\end{array}$ & Definition & $\begin{array}{l}\text { Category } \\
\text { of } \\
\text { Damage }\end{array}$ & Description of Categories & $\begin{array}{l}\text { Points } \\
\text { of } \\
\text { Damage }\end{array}$ \\
\hline $\begin{array}{l}\text { 沉积 } \\
\text { Chen Ji } \\
\text { Deposits }\end{array}$ & CJ & $\begin{array}{l}\text { Deposits on } \\
\text { the invert of } \\
\text { the sewer }\end{array}$ & 1 & $\begin{array}{l}\text { Deposits in the height of } 20-30 \% \text { of } \\
\text { the sewer }\end{array}$ & 0,5 \\
\hline
\end{tabular}




\subsubsection{Conclusion}

The most obvious difference between the German and Chinese regulations is a different handling/ viewing of direct inspection. For safety reasons, the German standards and instructions describe how to avoid direct inspection, which is not the case in the Chinese regulations under consideration. Furthermore, both sets of regulations specify a minimum diameter as a criterion for feasibility. Here the German minimum value is $50 \%$ higher than the Chinese one. Coupled with the other criteria regarding water level and flow velocity on the part of the Chinese plant, conditions arise under which the safety of the inspector carrying out the work cannot be guaranteed. Due to the preceding cleaning with regards to the German inspection, as well as the watertight sealing of the pipe work against further inflows, the safety conditions for the inspector in Germany can be considered to be safer. However, occupational health and safety is important in both variants, as can be seen from the need of protection through teamwork.

In both sets of regulations under consideration, the operating positioning of the camera is the same for indirect inspection. Accordingly, the lens must be centred in the direction of inspection and in the centre of the sewer cross section, therefore in the centre of the profile's cross section. The DWA-M 149-5 first specifies an approximation to the location of the finding in axial direction by swivelling the camera during a sighting. Then the camera should first be swivelled in a horizontal position and finally the lens should be centred on the object in a vertical direction. For this purpose, the regulations state the reason for the orientation aid for the inspector or the subsequent second observer (engineer). Such a regulation is not mentioned in the Chinese reference works. The CJJ 181-2012 describes a different starting situation for the indirect inspection measure than is the case in German. Accordingly, it is not planned to clean and block further inflows in the course of the standardised indirect inspection. Therefore, the indirect inspection, just like the direct inspection, is carried out during operational mode, provided that a certain criterion is fulfilled. This criterion is described with a maximum filling degree of the sewer cross-sectional height of $20 \%$, with respect to the cross section. If the permitted filling level is exceeded due to normal operation, suitable measures must be taken to reduce the flow height down to the specified criterion. In CJJ 181-2012, several reasons for a stop due to bad conditions are listed. A stop of the indirect inspection is required if an obstacle prevents the camera from moving forward, if the lens of the camera is dirty or overflowing with water, or if visibility is impaired by the appearance of fog. The speeds at which the sewer robot moves in the sewer section is regulated to a maximum speed of maximum $0.1 \mathrm{~m} / \mathrm{s}$ for a diameter $\leq \mathrm{DN} 200$, as well as not more than $0.15 \mathrm{~m} / \mathrm{s}$ for diameters $>$ DN 200 with the direction of movement in the direction of flow (CJJ 181-2012 2012). The HKCCEC2009 also mentions a third speed in addition to the above-mentioned speeds, for an application in the DN $>300$ range. There the maximum speed is limited to $0.2 \mathrm{~m} / \mathrm{s}$. For comparison, the German version has omitted a recommended speed specification. The only speed mentioned is one that allows the inspection to be followed without interruption on the basis of the recordings. This means that a moderate speed is chosen. This allows a secondary 
evaluation based on the given conditions, such as the image rate of the camera and visibility conditions [3].

\subsubsection{Management / Financing}

\section{Sewer Database and Sewer Information System}

The main task of a sewer database (SDB) is the documentation and updating of existing data and inspection results to ensure a coordinated and future-oriented maintenance of sewerages. The SDB provides in alphanumeric form the basis for the location verification, planning, construction, operation and maintenance of the drainage system. Consequently, it provides the basic prerequisite for maintenance and plant monitoring. Additional software for hydraulic network calculations, valuation or condition assessment is linked to an existing SDB and serves as an instrument for the engineering processing of the inspection results. In order to check the data and to process them further, today's technical possibilities require a graphic representation by linking to a sewer register [Pecher 91a]. The sewer register is connected to existing sewer databases by means of an appropriate interface configuration. The sewer register offers advantages when applications with large amounts of data and short access times are required. It offers a clear data management with high user comfort [ATVA145]. The sewer register offers the possibility of linking data, texts and images with their geographical location to one information unit. Together with the indirect discharge cadastre, which is used to monitor wastewater collection from industrial companies, it is also referred to as a sewer information system (SIS) [Sawat94] [FI-DWInf].

A sewer information system is thus a system for the recording, keeping, maintenance, illustration, analysis, processing and exchange of information on drainage systems outside of buildings. The quality of the results produced by a SIS is derived from the quality of the geodata stored in the sewer database. As these data serve, for example, the documentation of inventory, are used to produce maps or provide information for statements and expert opinions, as well as being the basis for planning and model calculations, they represent an enormous value. Maintaining these values and ensuring the quality of the geodata in the procurement, creation and administration of the data are part of the core tasks of every SIS and are the prerequisite for the efficient use of a sewer information system. Sewer information systems enable, based on a central sewer database, the creation of comprehensive and over-arching inventory documentation and operational information systems through software for sewer inspection and for the processing and evaluation of inspection data.

\section{Software for Sewer Inspection and for Processing and Evaluating of Inspection Data}

The aim of the sewer inspection is to derive the documentation of the structural condition from the recommendations for action to maintain the sewer system. A uniform, generally valid and automated description of the different conditions in the sewer 
system is mandatory. The coding system to be used is described in DIN EN 13,5082, in conjunction with the DWA leaflet DWA-M 149-2, which provides application recommendations (see chapter 2.3.1). The description of the condition is done by means of a main code, characterisation and a corresponding quantification. Operators can learn sufficient expertise and the application of the code in special "Sewer Inspection Courses". The digital sewer register is maintained in a sewer information system. In addition to the pure plan information, such systems provide the data basis for the manifold tasks of sewer operation. The hereby listed attributes concerning the objects of the sewer system serve as a basis for the sewer inspection. The sewers and structures to be inspected are digitally transferred to the sewer inspector. As described in leaflet DWA M-194-5, efficient and economical data management and a continuous flow of information in digital form is required. This data cycle from the SIS to the inspection vehicle and back again is outlined in the DWA-M 150 information sheet. Here, the master data of the sewer sections and structures are transferred to the inspection vehicle in digital form. The operator validates the master data on site and extends the data by the description of the current condition. At the end of the sewer inspection, the data are digitally transferred again for further processing.

On the inspection vehicles or mobile camera systems, therefore, a databasesupported software must be used to enable digital data exchange and electronically supported damage description. Inspection software products are highly specialised products which, on the one hand, have to communicate with the hardware of the inspection vehicle/ crawler and, on the other hand, have to take into account the common specifications for the coding system, data management and data cycle. Inspection software products are developed or distributed by several hardware manufacturers. There are also free software manufacturers who have adapted their inspection software to the hardware of different manufacturers. An inspection software must document the condition of the sewer system. In addition to the coding, a video and optionally a photo is usually added to the status. To be able to locate the documented status, the station of the condition must also be specified. Through the coupling to the BUS system, the inspection software receives relevant information, such as the distance travelled, or sends information for the insertion of text into the video. A further important task is the control of the video recording. For this purpose, a video grabber must be available to encode the analogue video signal into a file format. The video grabber provides an API to control the video recording and the quality of the video file.

\section{Cost Implications of a Regulated Recording and Management System for Sewer Data}

The construction and operation of the drainage facilities, as well as their maintenance, require a large amount of financial resources. At the same time, the public infrastructure of drainage facilities is often one of the largest asset of cities and municipalities [8]. Therefore, the economic aspect plays an important role for the operator. It is important to keep the costs as low as possible in order to ensure efficient use of the financial resources of the cities and municipalities. It is also in the interest of the cities and municipalities to maintain the financial value of the sewerage system for as 
long as possible. When the sewerage system is built, it is given a predicted operating life, which determines the duration of depreciation. It is therefore the intention of the operator to maintain the condition of the sewerage system as good as possible in order to extend the depreciation period, if necessary, and thus reduce its annual costs, or to ensure that the sewerage system continues to exist beyond the depreciation period. Further costs are incurred by the municipalities and local authorities as a result of the rehabilitation or even new construction of damaged drainage components. Since it is logistically and economically impossible to keep all sewers in a faultless condition at all times, plans must be drawn up for the necessity of rehabilitation measures. These plans provide information about the urgency of possible measures and can be used for a direct comparison between sewer sections in order to decide which sewer section is most in need of rehabilitation. The basis for these plans is a detailed and precise condition assessment, followed by a technical classification and subsequent evaluation of the conditions.

In order to avoid a conflict of interests, a differentiation between the persons carrying out the condition recording and the classification, i.e. an evaluation of the condition is recommended (LfU 2010; ATV-M 149, 1999).

During the operation of the sewer system, questions of economic efficiency further arise. For example, the operation of wastewater treatment plants, whose efficiency is directly dependent on the throughput. Extraneous water entering the sewerage, which for the most part does not require treatment, is also treated in the treatment plants and occupies capacity. These additional capacities result in increased costs for operation. In order to keep the costs for the transport and treatment of the wastewater low, the condition of the sewerage must be checked in order to detect damaged sewers and reduce the infiltration of extraneous water to a minimum. It is also important for the operation to maintain the structural conditions in order to enable proper operation under favourable hydraulic conditions and to ensure that parameters such as flow velocity, shear stress and gradient are within a desired range. This is guaranteed by a condition assessment or a rehabilitation in the later course of the project.

\subsection{Application of Advanced Sewer Inspection Technologies in Jiaxing}

\subsubsection{General Notes}

\section{Analysis of the Conditions on Site}

The initial meeting in Jiaxing, China was held to investigate the situation on site.

The examination showed that the present sewer systems lack a proper drainage of upcoming sewage water and entering groundwater. Hence, a certain water mark is always present in the system that allows solid matters to be collected in the sewers and shafts. This situation complicates the inspection and excludes several inspection systems established in Germany. 
The meeting indicated that the FastPicture method is already available and is being used by the Chinese partners. Even though the system provided by JT-elektronik offers higher video quality as well as robustness, this option was rejected.

It was decided to design a new and customised system based on the SKI method. To meet the requirements on site properly, the new system should comprise the following specifications:

- possible visual inspection of the sewer above water level

- adjustable camera system in height depending to the water level

- adjustable transport system to the sewer dimension

- portability of the inspection system

- simultaneous cleaning and inspecting of the sewer

In the following the design and implementation of the first prototype as well as the commissioning and tests are outlined.

Application of prototype I shows the former prototype of the inspection system. Now the transport vehicle is based on a sledge system with three blades (see Fig. 7.5). The blades facilitate the movement of the system in the sewer by slicing the solid deposits. Additional wheels attached to the blades serve to minimize friction and therefore abrasion of the sewer material. The size of the system is continuously variable corresponding to the dimension of the sewer.

In total, two setups were built to cover the sewer diameters from 150 to $300 \mathrm{~mm}$ and 400 to $800 \mathrm{~mm}$, respectively. Furthermore, the symmetric arrangement of the three blades offer an unproblematic removal of the system in case of an accident (e.g. tip over of the inspection system).

The drive of the system is based on a customised cylindrical nozzle (see 7-10) that offers the combination of controllable drive and cleaning by adjusting water flow and pressure. The insets of the nozzle are available in VA-steel and ceramic which is more robust against abrasion by solid particles in water. The angles of the inlets were adjusted to obtain an optimised jet for driving (wide angle) and cleaning

Fig. 7.5 Prototype I (FiW)

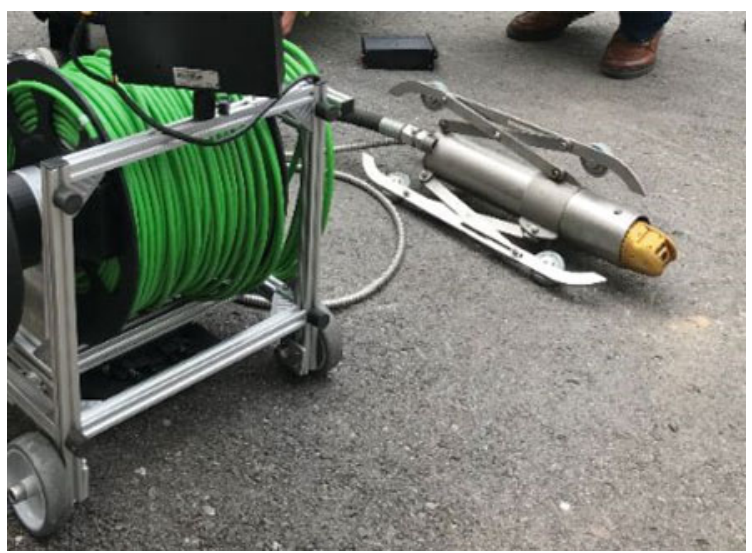


(small angle). The nozzle can be driven by a $3 / 4$ " or 1 " hose, depending on the scope of application. To prevent tilting of the inspection system, caused by the hose, a rotating joint was integrated (Fig. 7.6).

Visual inspection is conducted by use of a pan and tilt camera mounted on the transport system. The height of the camera can be adjusted to be centrally oriented in the sewer with a diameter range of 150 to $800 \mathrm{~mm}$. This ensures an unobstructed view independent of the water level. The camera offers a video signal with a resolution of $500 \times 576$ px, manual focus and automatic aperture manipulation.

The system provides an integrated cleaning function during inspection. The water flow through the nozzles induces a jet removing water and solids from the camera surface and lens when swivelling the camera head by $90^{\circ}$ aside. This ensures a clear visibility throughout the inspection.

The system can be controlled (i.e. light, pan, tilt) by a portable structure (see Fig. 7.7, left) with an integrated battery pack, a tablet for video inspection, and

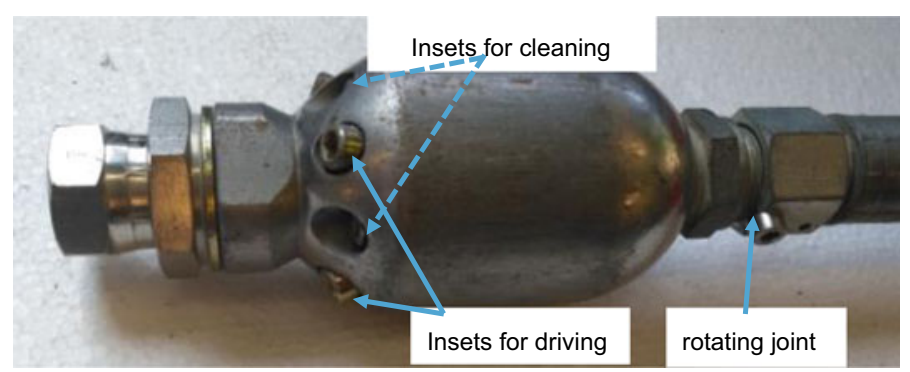

Fig. 7.6 Customised nozzle for prototype I. (JT Elektronik)
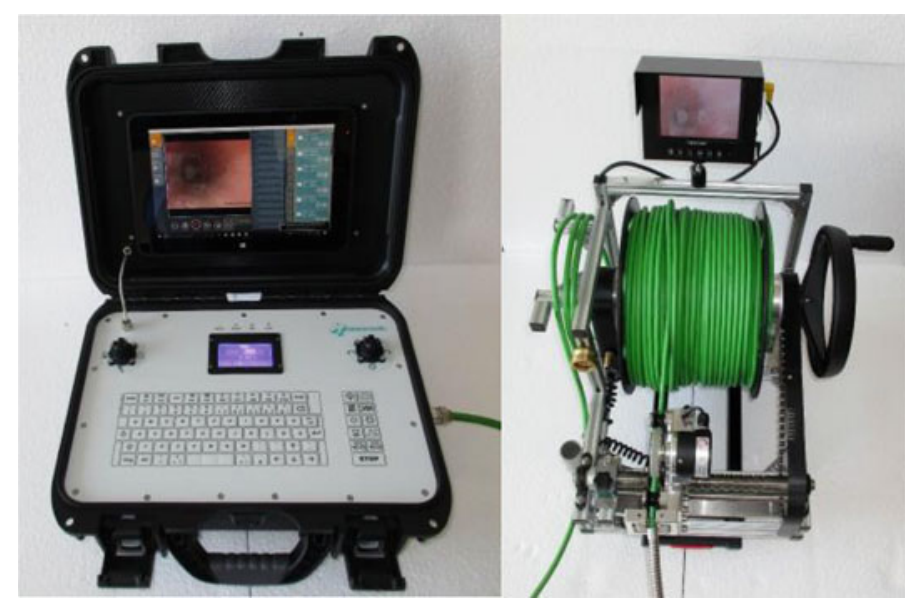

Fig. 7.7 Portable control system (left) and cable drum with integrated video monitor (right). (JT Elektronik) 
Fig. 7.8 Test of prototype-I in Wiesbaden. (JT Elektronik)

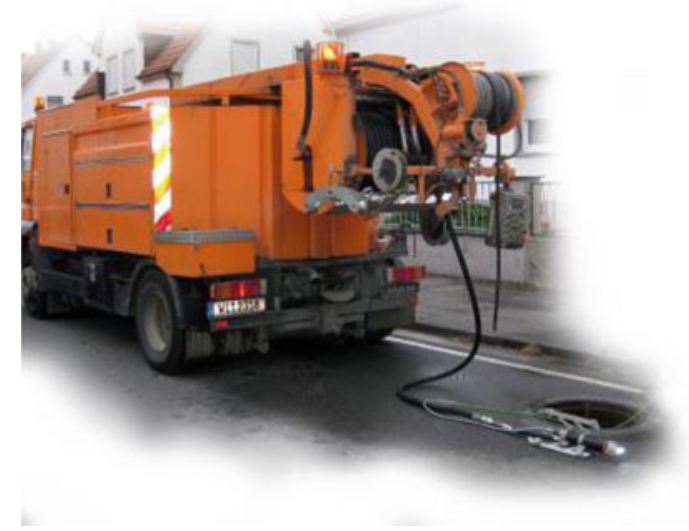

a human-machine-interface for camera control via buttons, joysticks and a touch panel. The connection to the camera is realized by a cable drum (see Fig. 7.7, right) with a cable length of $150 \mathrm{~m}$, a video monitor, and an integrated cable length counter being displayed in the control system.

Commissioning and testing of the system was executed under ideal conditions on the company premises of JT-elektronik GmbH Lindau and on a test area in Wiesbaden, Germany (see Fig. 7.8). The vehicle was placed into sewers with different diameters ranging from 200 to $900 \mathrm{~m}$. The sewers partly contained water and solids up to $15 \%$ of the diameter. The system was connected by a $3 / 4$ " water hose to a flushing vehicle. The vehicle was equipped by JT-elektronik $\mathrm{GmbH}$ with a high-pressure pump and tank system providing a water flow of $120 \mathrm{l} / \mathrm{m}$ and maximum water pressure of 160 bar. The system was successfully commissioned and the functionality (i.e. proper driving) was verified.

\subsubsection{First Demonstration of the Inspection Process}

To test the prototype under real conditions, a meeting in China was arranged (see Fig. 7.9). The participants comprised Tobias Jöckel (JT-elektronik), David Eisenhauer (bluemetric), Jan Echterhoff and Marc Jansen (FiW).

The tests were executed in a municipal sewer system in Jiaxing, China which reflects the conditions in Chinese cities. The tests showed that the huge depth of the shaft and the absence of climbing irons, particularly present in China, severely impede the insertion of the inspection device. Furthermore, the soiling in the sewer was found to be stronger than initially assumed. During the tests it was apparent that the height offsets throughout the sewer as the major challenge, since the inspection system could get stuck. To avoid this and improve the handling of the inspection system the vehicle was optimised in further steps described in the following. 


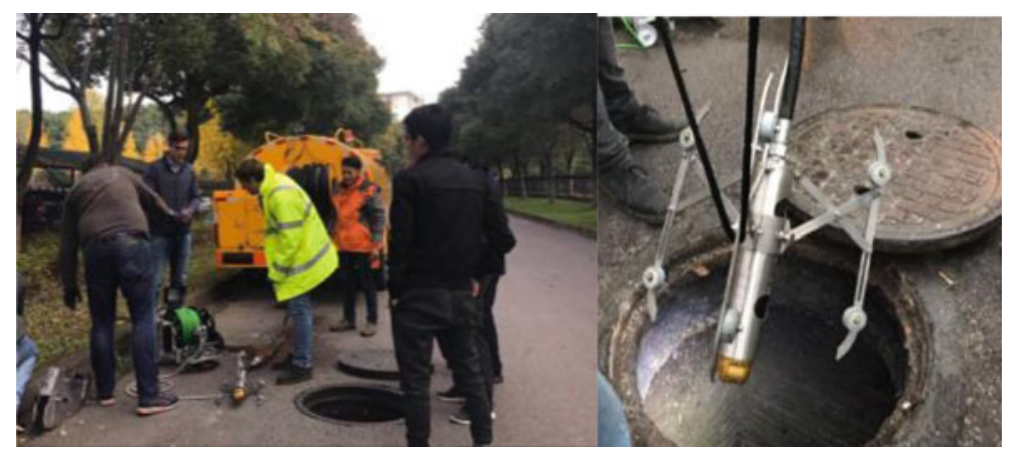

Fig. 7.9 First tests in Jiaxing, China. (FiW)

\subsubsection{First Assessment of the Inspection Process}

The existing water level and the height offsets in the sewers require a floatable system. Therefore, prototype I was extended by two floating bodies, see Fig. 7.10. Floating bodies with increased length serve to better stabilise the system during floating; however, the increased length renders handling more difficult when the system is inserted into the sewer, especially when having small inlet diameters. Therefore, the system provides a mounting for two different sizes of floating bodies. The first one is applicable for sewer diameters from 200 to $400 \mathrm{~mm}$ and the second one for diameters ranging from 500 to $1500 \mathrm{~mm}$. The floating bodies can be mechanically adjusted to the diameter of the sewer. A keel for stabilization during floating was attached.

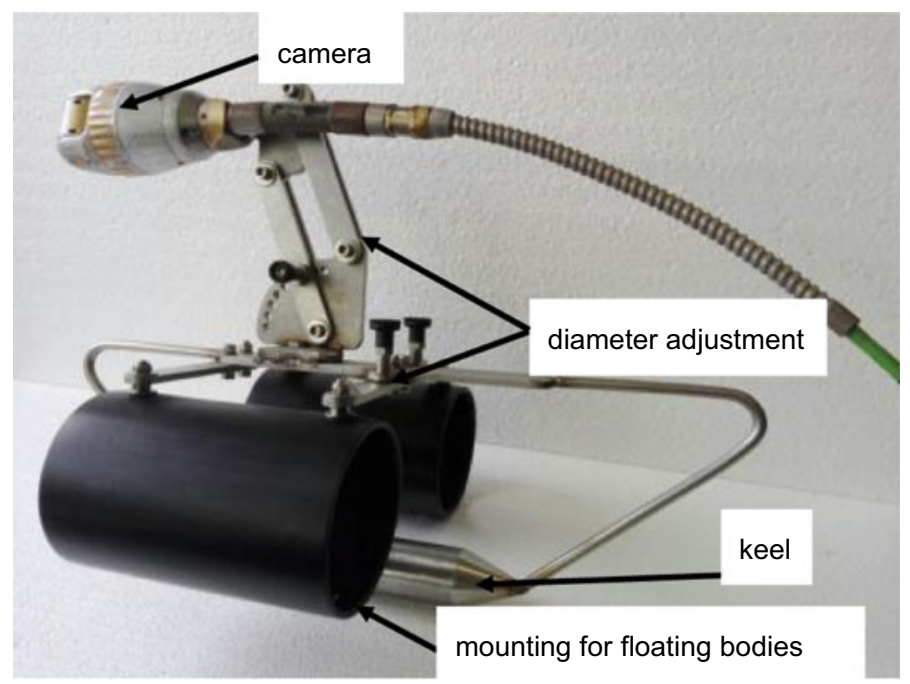

Fig. 7.10 Inspection system prototype II. (JT Elektronik) 


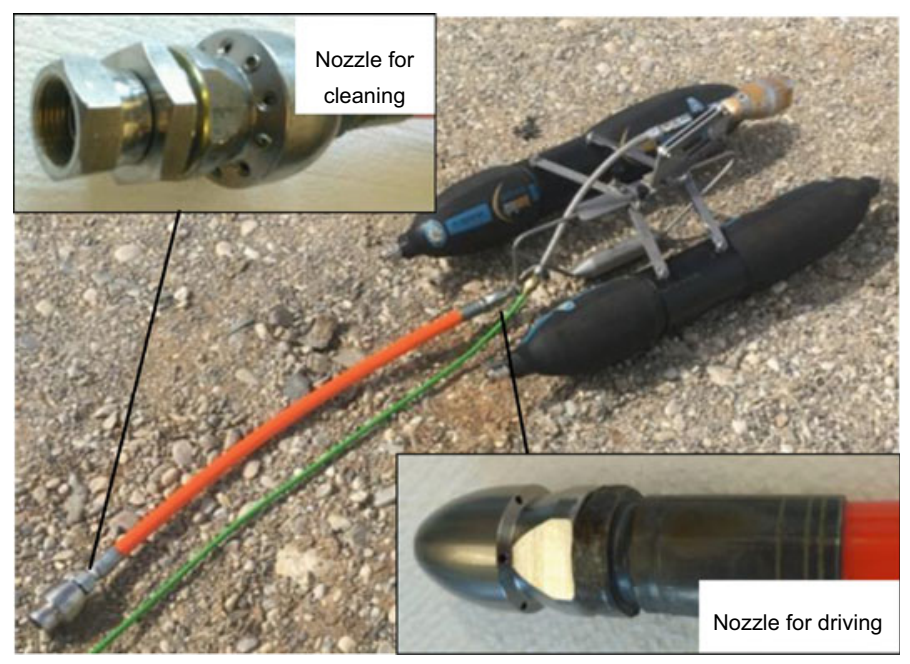

Fig. 7.11 Prototype II including floating bodies and nozzles. (JT Elektronik)

Due to the heavy soiling in the Chinese sewer systems the nozzle was replaced by a combination of two coordinated nozzles, see Fig. 7.11. The first is located in proximity to the vehicle right below the water surface and serves for driving the system. It also ensures a stable floating of the system itself. The second nozzle is attached to a tube approximately $50 \mathrm{~cm}$ behind the vehicle. This nozzle is pulled down to the bottom of the sewer and is therefore used to remove the soiling and clean the sewer. The system is also equipped with a rotating joint (comparable to prototype I) to avoid tilting of the inspection system.

To test the system under realistic conditions a test field in Munich, Germany was used. The test field consisted of a sewer system with a diameter of $600 \mathrm{~mm}$ and contained gravel and water up to $30 \%$. The tests were executed in cooperation with Huber Linden, Reinigung und Entsorgung GmbH.

Figure 7.12 shows the test setup with the inspection and flushing vehicle to drive prototype II. The inspection system was inserted into the sewer (see Fig. 7.13) and was driven by a constant water flow provided by the flushing vehicle. The video signal (see Fig. 7.14) was captured with the equipment in the inspection vehicle.

The inspection system was successfully tested and the functionality (i.e. driving and cleaning) was verified. The resulting speed and the cleaning performance appeared to be sufficient for the conditions in China. The optimised nozzle combination proved to have a positive effect on the stability of the system while floating. The video quality and the illumination of the sewer were satisfactory. 


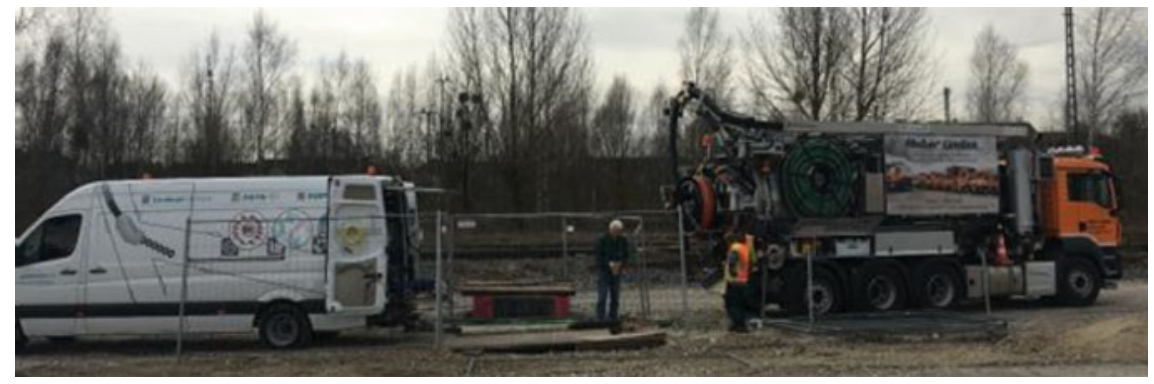

Fig. 7.12 Test setup in Munich. (JT Elektronik)

Fig. 7.13 Inserting the prototype II into the sewer. (JT Elektronik)

Fig. 7.14 Video signal of the inspection. (JT Elektronik)
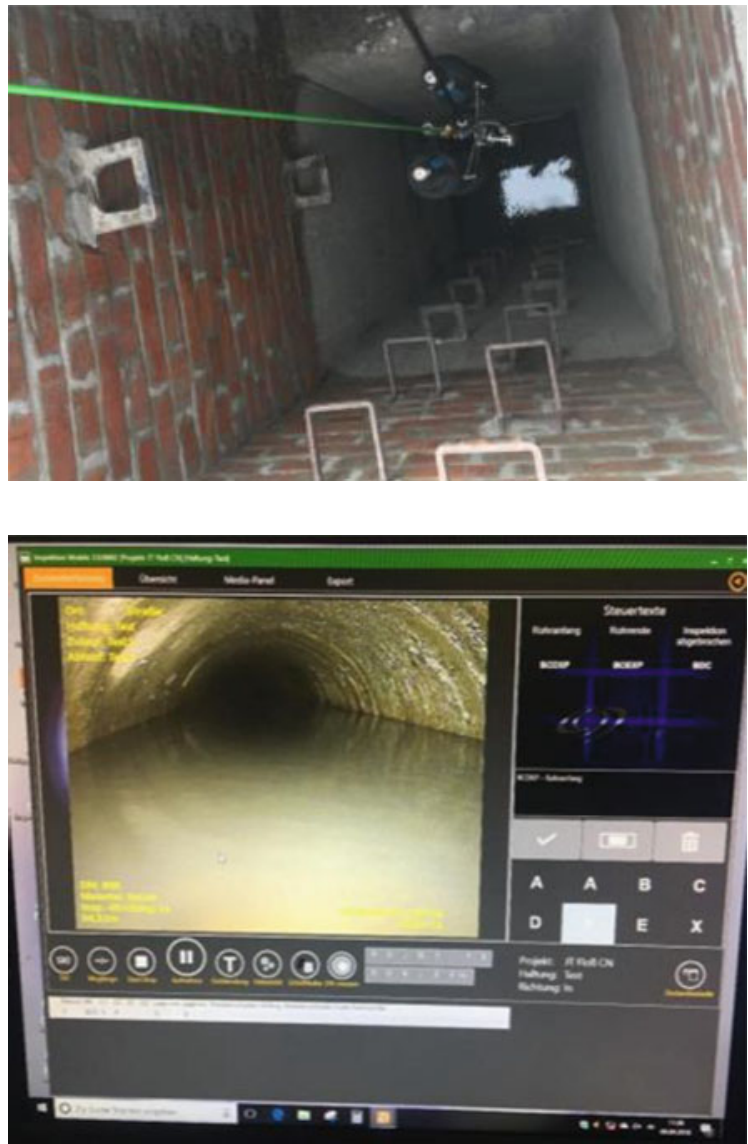


\subsubsection{Second Demonstration of the Inspection Process}

Due to the positive results of the previous tests, prototype II was transferred to China for final assessment.

The system was presented to the Chinese partners and a training was held to properly operate the system (see Fig. 7.15 and Fig. 7.16).

Final tests took place in the municipal sewer system. The insertion of the inspection system was practicable due to the high variability of this system in width and height. Various tests in canal systems with different diameters were carried out in cooperation with the Chinese partners. The handling and the evaluation of the actual performance of the system was practiced intensively.

Fig. 7.15 Final project meeting in China. (FiW)
Fig. 7.16 Training of Chinese partners in operating the inspection system. (FiW)
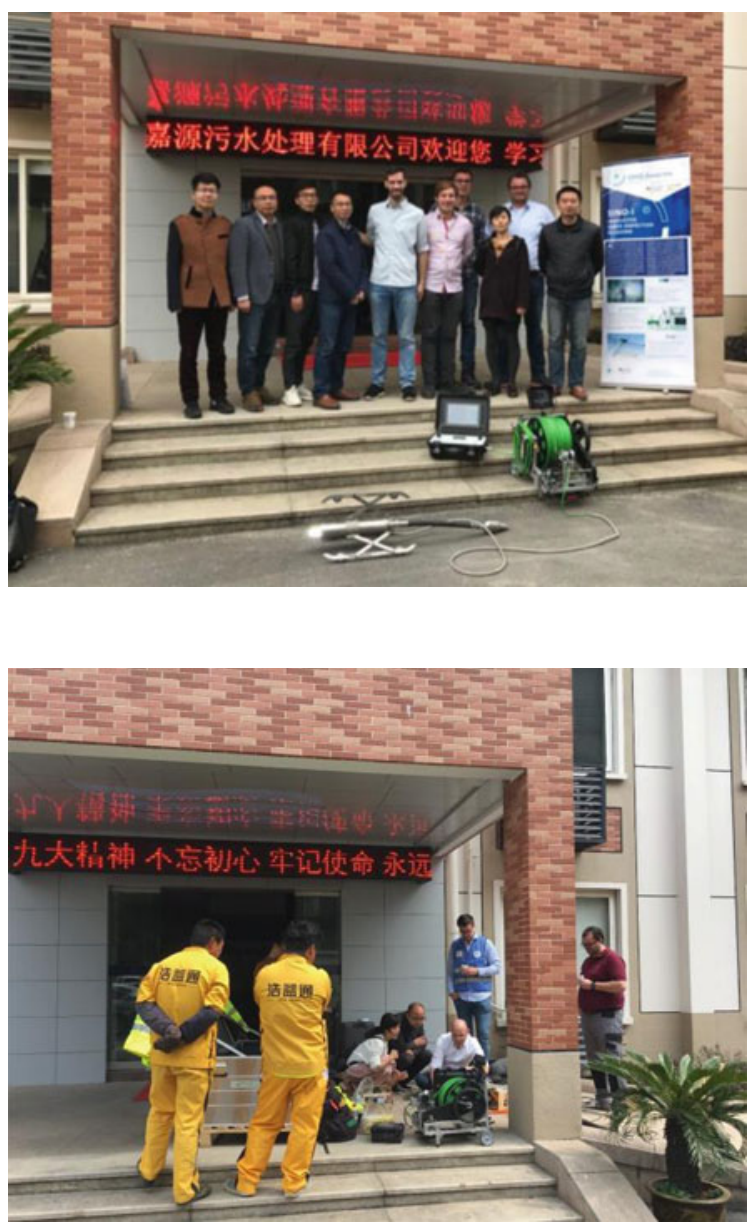


\subsubsection{Second Assessment of the Inspection Process}

The tests show that mechanical optimisations of the system described above improve the handling of the device significantly. Even when solid particles are given, the floating bodies ensure the movement in the sewer with a water level up to $60 \%$. The cleaning and driving performance of the nozzles were proven to be sufficient.

The applicability of the system to sewers with different diameters enables a flexible application to a wide range of sewer systems in China. Additionally, the mechanical structure of the systems allows a safe recovery in case of damage. The camera system enables a visual inspection of the sewer during cleaning, which is time-saving.

Beside the various advantages the following limitations were recorded.

Due to the overload of the Chinese sewer systems it is necessary to clean the sewer before inspection. Since there are no vacuum trucks available in China to remove the solid material from the sewer, cleaning options are limited.

The presented inspection system can be used for the majority of sewer systems in China. Nevertheless, the water and dirt levels vary within different sites which makes the system a system of limited application (e.g. low water level impedes floating of the device). Therefore, a combination of prototype I and II is advised. Subsequent to the tests, the system was handed over to the Chinese partners to proceed with further investigations.

\subsection{Management Systems for Sewer Data Evaluation}

\subsubsection{Technology Development}

\section{Requirements}

Within the framework of technology development, the choice of hardware and software depends on several factors. There are on the one hand project specifications, which were discussed in advance by the project partners involved and adjusted to the current situation on site. In this context, local conditions such as for example the level of knowledge of the skilled workers play a major role. On the other hand, a tailor-made condition abbreviation system has to be developed for this project, which is adapted to the local requirements.

Prior to the start of the project, the local conditions in Jiaxing were studied and the requirements for a sewer inspection system were defined through several site visits and meetings with the project participants. Thus the skilled workers should be able to independently carry out inspections under the given conditions with the developed system. Instructions and the daily work should be possible to be passed on to each other without the support of skilled workers. The hardware should be compatible with the local infrastructures, e.g. flushing vehicles, or be connectable to them. Furthermore, it should be possible to build up a permanent data stock through data exchange, from which the condition of the local sewer system can be derived. 
From these requirements, framework conditions for the implementation of the overall system can be derived, e.g. which hardware and software components should be used.

\section{Local Boundary Conditions}

Apart from the project specifications, the local conditions must also be taken into account. As opposed to Germany, training and a certain level of qualification of the skilled workers cannot be assumed, so that the level of knowledge of the skilled workers varies greatly and the handling of the hardware and software should be kept as simple as possible. In addition, cultural and administrative differences in the field of sewer inspection in China lead to different approaches and operating sequences. For the test runs during the first practical test in Jiaxing, the condition was communicated in advance that the sewer sections to be tested should be pushed off. Since the administrative classification of the responsible wastewater companies is not done locally, but according to the diameter of the sewer section, the sewer sections are still in operation when the test runs are started. This necessitates an adaptation of the system to the above-mentioned conditions.

\section{Condition Abbreviation System \\ Hardware}

In addition to the specific JT Elektronik hardware (slide construction and case system), the Tablet Pokini Tab A10 with the following specifications relevant for the technology development was used:

- Display size: 10.1 " with $1920 \times 1200$ pixels

- Operating system: Windows 10

The size and resolution of the display determines the available space for the software application. For this reason, the UI design of the software was based on a minimum resolution of $1920 \times 1200$ pixels and, thus, a complete display cannot be guaranteed at lower resolutions.

The decision to use Windows 10 as operating system is based on the wide distribution, the regular supply of updates as well as the positive experiences with previous software projects for sewer condition recording of bluemetric software $\mathrm{GmbH}$. Since the Chinese project partner is already using the operating system in other areas, it can be assumed that they have knowledge in handling of the operating system.

The used camera delivers an analogue video signal, which must be converted into a digital signal for further processing. An external analogue-to-digital converter (A/D converter) is used for this purpose. In agreement with JT-Elektronik, an A/D converter from Sensoray (Model 2253) was employed here. This model has a low latency of the video image, so there is almost no delay between the real video image and the display in the software. This is especially worth mentioning in connection with hardware control, since a time delay of the video image does not reflect the current orientation and position of the camera.

In addition to the transmission of the video image, the software must receive the current and already travelled track of the hardware for complete documentation of 
the sewer condition. This is the only way to locate the relevant position in the sewer during later evaluation. The connection was made via a serial BUS system developed by JT-Elektronik for transmission of the track length. Should the hardware detect a change regarding the length of the track, this information is transmitted to the software via the BUS data connection and thus displayed by it.

\section{Software}

As previously explained, a tablet with the Windows 10 operating system was selected. The possible software technologies for creating software are generally depending on the operating system used. bluemetric software $\mathrm{GmbH}$ has decided to develop software based on .NET technology. .NET is a platform developed by Microsoft for the development and execution of application programmes and is integrated in the Windows operating system. The advantages of software developed on the .NET platform are the optimal integration into the operating system, already existing functionalities that do not have to be implemented by the user, independence of the Windows version used as well as continuous further development and error corrections by the manufacturer with automatic updates via Windows updates. Windows Presentation Foundation (WPF) was used for the development of the software interfaces. WPF is included in the .NET platform and allows free and individual design of the individual interface elements such as buttons and selection lists. WPF furthermore allows the separation of interface (View) and logic (Viewmodel). The interface can thus be edited independently of the logic. This was strictly adhered to during the development of the software. The relational database system SQLite was used for permanent storage of the data. SQLite has the great advantage as compared to other database systems that it does not require any additional server software. For use, only a freely available programme library must be integrated into the executing software, which then provides all necessary database functions. In addition to the freely available SQLite programme library, the following non-free programme libraries were used: Syncfusion and Datastead TVideoGrabber. While the Syncfusion programme libraries provide a variety of features that extend the .NET platform. Syncfusion functions were used for developing the software to generate PDF documents because the .NET platform does not offer them. In contrast, the digital video signal must be stored in a video file to fully document the condition of the sewer. To reduce the file size of the video file, it must be compressed. Video codecs are used for compression. Since the .NET platform does not provide any functions for this, the programme library TVideoGrabber from Datastead was used.

\section{Object Structure}

All collected data is organised into projects by the developed software. The set-up of a project is always the starting point of every sewer inspection. The projects can be organised here according to any thematic scheme, such as for example streets, villages and towns or by date. As master data, they themselves contain simple attributes such as name, creation and modification date. Figure 7.17 shows the structure of projects and contained objects. 


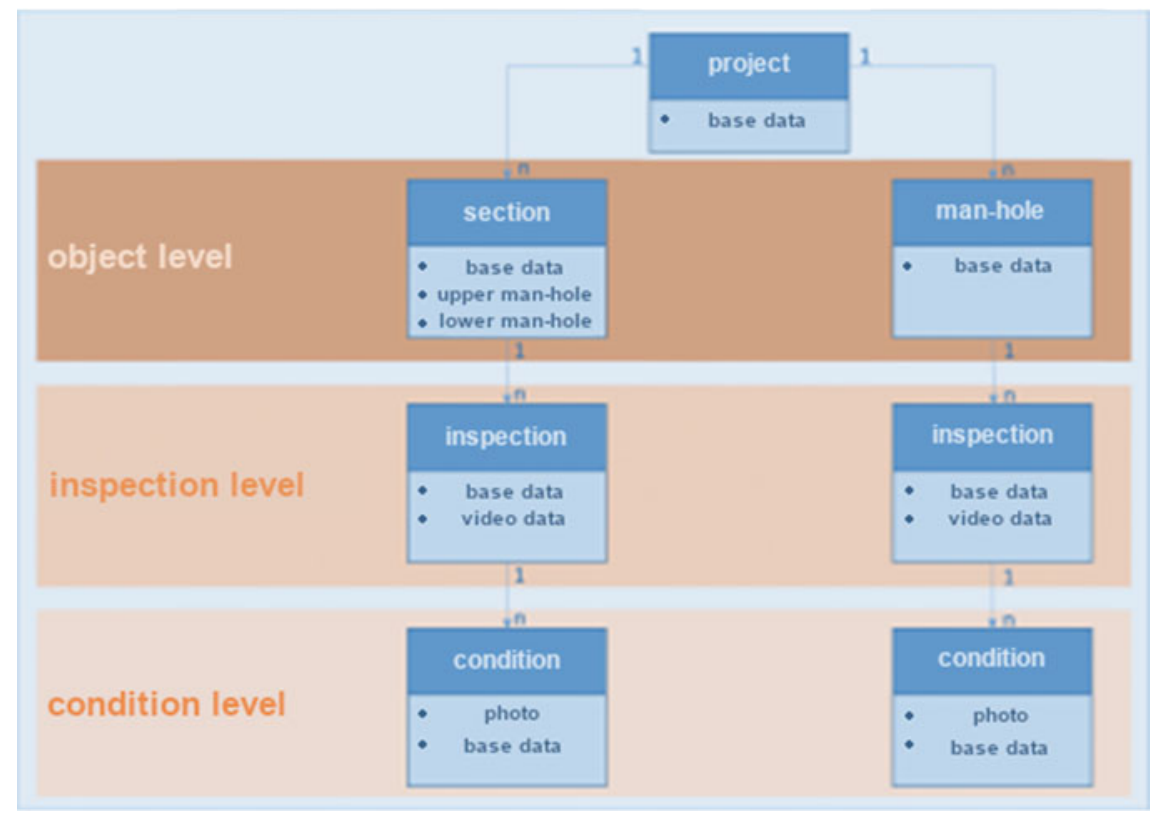

Fig. 7.17 Project structure

In each project, any number of main sewer objects can be recorded in the object level. According to the project specifications, only sewer section and manhole objects are implemented here for the time being, since in China inspections are mainly carried out in the public main sewer system and not in the house connecting pipes. Each sewer section contains master data based on the DWA and links a manhole at the top and a manhole at the bottom. Standardised master data can also be added to a manhole. On the inspection level, both object types can include any number of inspections. The inspections of both types of objects also have DWA standardized master data and a linked video for condition recording. The last level is the condition level, on which there can be any number of conditions per inspection. The conditions contain - similar to the condition objects of German standards - typical master data such as stationing and condition abbreviations. As a further possibility a photo can be linked. A table with the master data of the conditions can be found in Annex B, the structure of the condition abbreviations is explained in chapter 4.1.1.3, whereby the conditions contain condition abbreviations according to the table in Annex D.

\section{Process Programme Sequence}

The programme (see Fig. 7.18) consists of a main view in the middle, tab elements in a bar on the left, a title bar in the upper area and an object list in the right area. The tab bar allows the user to change the view at any time. In this way, for example, settings - such as the language - can be made during an inspection or the master data of an object can be retrieved or adapted. 


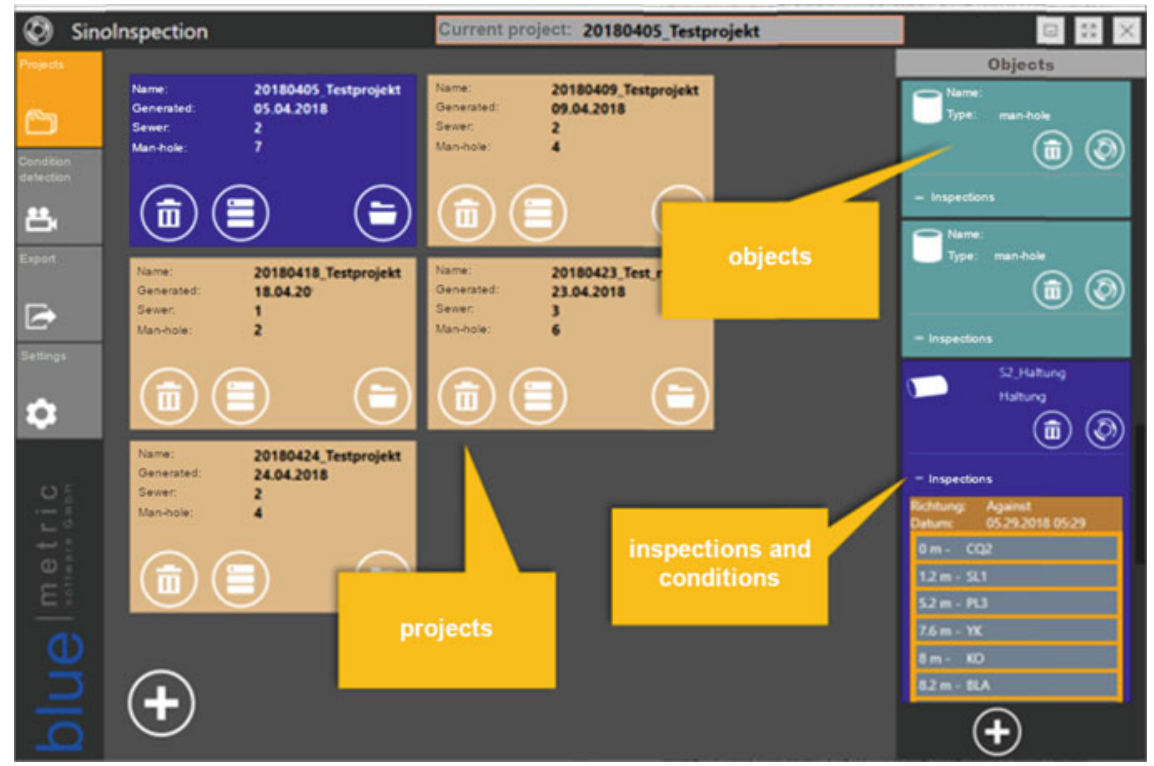

Fig. 7.18 Programme surface/interface - project view

The programme sequence for carrying out inspections is shown in Fig. 7.19. The starting point is always a project.

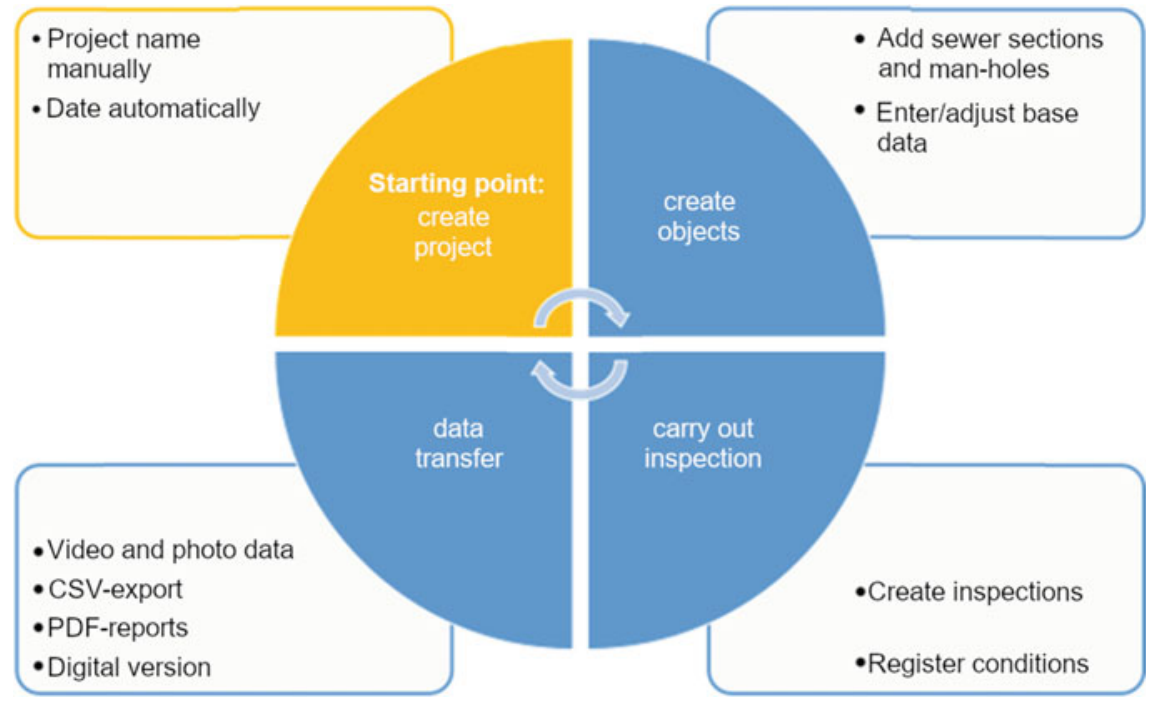

Fig. 7.19 Programme sequence/to carry out inspections 
In the project view, the user can start a new project using the button in the lower left corner. As soon as the user starts a new project or opens an existing project, the view is automatically switched to the condition recording view and the existing objects of the current project are loaded. After opening the project, in the next step new objects can be generated via the button in the lower area of the object list. Then the master data view of the new object opens. After confirming the master data, the set-up of an object is completed. Next, inspections can be carried out for the existing objects. When an inspection is started, the video in the condition recording view is started automatically. Now, while the video is running, a condition abbreviation can be selected in the right area, next to the video, and thus a condition status can be added. The video window is reduced in size and the master data of a condition can be entered. After performing sewer section inspections, a sewer section report with all relevant data can be generated via the export view. Additionally CSV files (Comma Separated Values) with the master data of the project objects can be given. These should offer a possibility of data transfer (see also chapter 4.1.4.5 Data Transfer) for the customer, also because these files are easily adaptable from outside. In addition to these two exports, projects can be exported as a whole, with the sewer section reports and CSV files also included.

\section{UI-Concept}

The development of the user interface (UI) plays a special role in the development of the software. The UI is the programme interface on which the interaction between user and machine (human-computer interaction) takes place. The goal is an intuitive and efficient operation of the software with minimal need of instruction or training.

\section{Touch-Control}

The tablet used has a touch display and thus allows operation with the finger instead of the mouse pointer of an externally connected mouse. When the screen is touched, a click action is triggered for the UI element in this position, similar to the mouse click when operating with the mouse. However, with touch operation, the precision is significantly lower as compared to mouse pointer use. As a result, the operation of small, closely spaced UI elements with the finger is more error-prone.

\section{Size of Control Elements}

Controls are all UI elements that interact with the user, including buttons, selection lists, lists, text fields, etc. In the case of touch operation of the software, the control elements must be designed and placed in such a way that error-free operation is ensured. The buttons used have a diameter of approximately $1.5 \mathrm{~cm}$ and a minimum distance of approximately $0.5 \mathrm{~cm}$. With the selected diameter, the buttons are not too small and can easily be hit with the finger, the distance avoids accidentally hitting an adjacent button. When developing the UI, overlapping programme windows and views were avoided as far as possible. There should be only one UI layer in which the current view is shown. 


\section{Integrated Programme Navigation}

The software provides the user with programme guidance, which leads to a clear and intuitive programme flow and minimizes incorrect entries. In the main view the current topic to be worked on is displayed, this must first be completed before the next processing step can be carried out.

\section{Simplified Condition Abbreviation System}

Chapter 2.3.3 described the structure of the Chinese condition abbreviation system. In the software, the main code must be selected in the first step; if it is an error code, the level of deficiency must then be selected (see Fig. 7.20). If the main code is an event, no further specification is necessary (see Fig. 7.21). Finally, the selection must be confirmed.

\section{Localisation}

The development of a localisation concept is decisive in the context of the research project, as the software to be used must be understood by Chinese specialists and decision-makers, as well as by German project partners who instruct the Chinese specialists on site. This is also necessary in view of further international software projects, where the possibility should exist to make other languages available. In the software, it is therefore necessary that the language can be changed during runtime and that all texts are changed to the selected language. For this purpose, a selection menu is available in the settings view which can be used to specify the desired language. By changing the language, there must be dynamic text elements in the software views that display the text of the selected language package. The concept of DataBinding is used for this purpose, in which adjustable variables are used in the views, which are controlled by the logic in the background. The language texts displayed on the user surface are organized in XAML-based language files, in which the individual language text elements are each stored in a key-value pair. Here the key is embedded in the views and the associated value from the language file is then displayed for the user. This procedure/ process also offers the possibility to adjust language texts if they contain errors or if the text contents of a text element have to be changed. A further advantage is that the texts can be adjusted on site. No special software is required for adjustments, changes can be made with any text editor which is available on all operating systems. Furthermore, this concept allows the easy addition of further language packages by generating language files with the same keys and values adapted to the new language. This procedure also has the advantage that Chinese characters, i.e. texts in Unicode16 format, can be inserted

Fig. 7.20 Level of deficiency

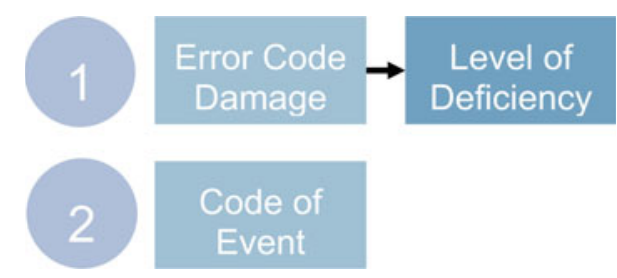




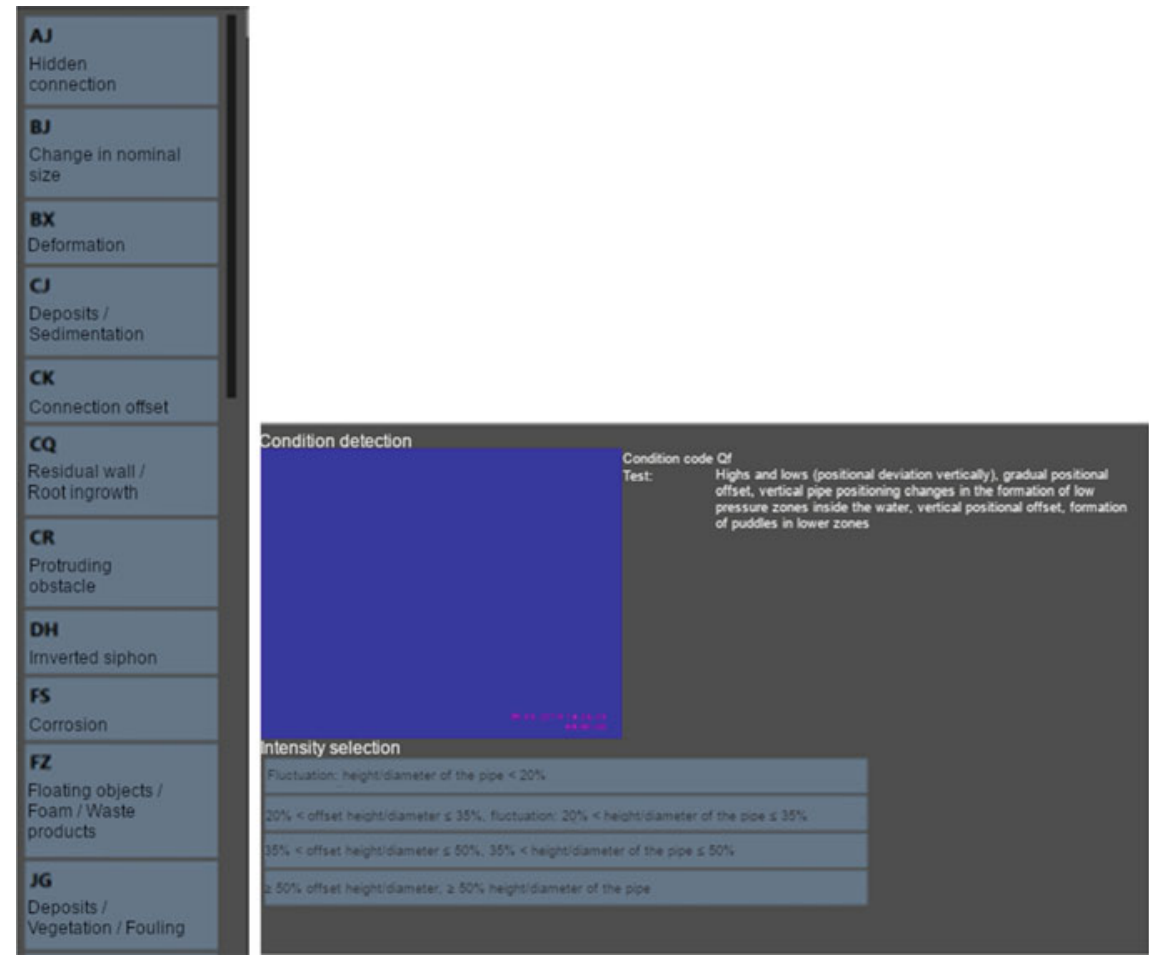

Fig. 7.21 Condition code specification

directly into the language files, which are subsequently only displayed by the software in their original form. Figure 7.22 shows the comparison of the condition recording view with concerning German and Chinese language settings respectively. Further programme views with localisation comparison can be found in Appendix E.
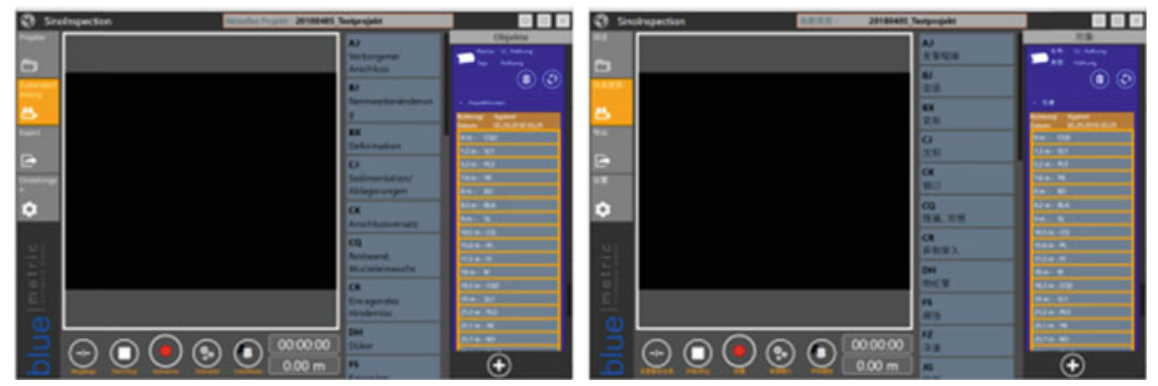

Fig. 7.22 Programme view in German and Chinese language 


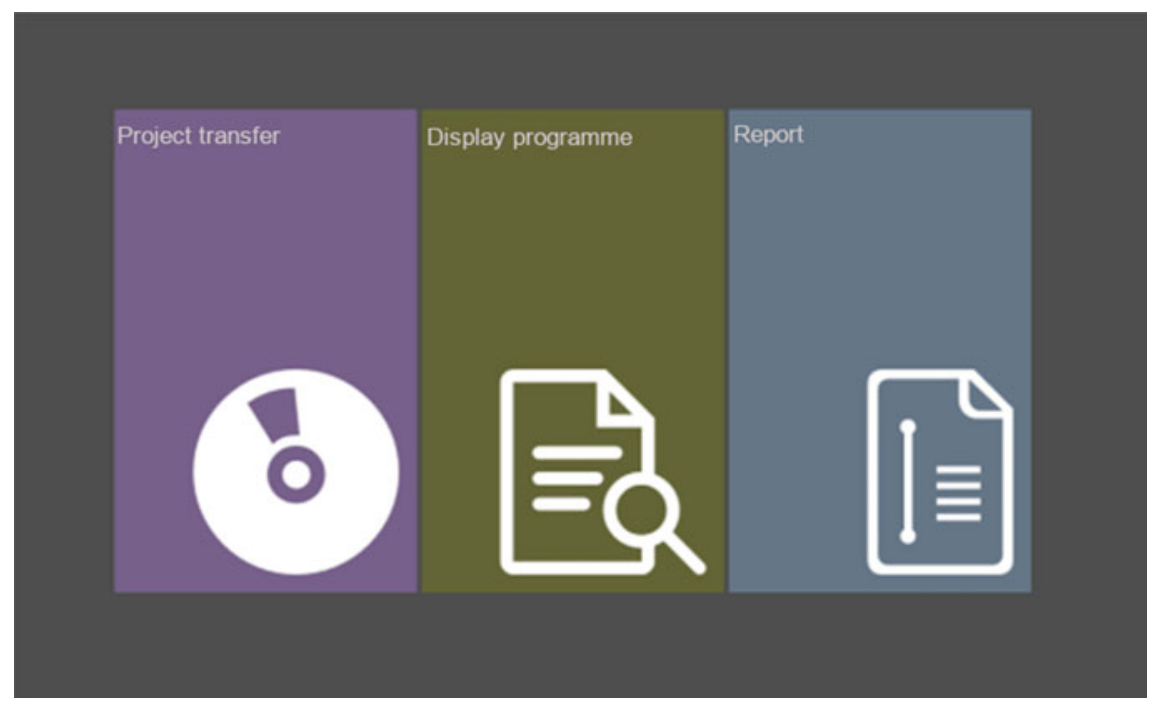

Fig. 7.23 Interface of data transmission

\section{Data Transmission}

In order that the recorded data can be used for further processing, the software offers various possibilities for data transmission as shown in Fig. 7.23.

\section{Project Transfer}

During project transfer, all data recorded is displayed. As opposed to the exchange formats used in Germany based on DIN EN 13,508-2, there is no guideline in China for a standard based exchange format. However, in order to be able to pass on the recorded data, the export of a text file in CSV file format was implemented. All master data and sewer condition data recorded with the software are displayed in this file. The file can already be opened and read with simple text editors. Many programmes allow the import of files in CSV format.

\section{Display Programme}

The visualisation programme allows the data to be transferred to an independent programme for viewing the recorded data, yet the data cannot be changed. The display programme (see Fig. 7.24) can be run independently from the software for recording the sewer condition and thus allows flexible transfer to other computers without the additional, prior installation of further programme files.

\section{Reports}

With the software, a report can be created in Microsoft Word and PDF file format for each inspection performed. The report contains all relevant documented data of the created objects. The recorded condition codes are displayed in both tabular and graphical form (see Fig. 7.25). 


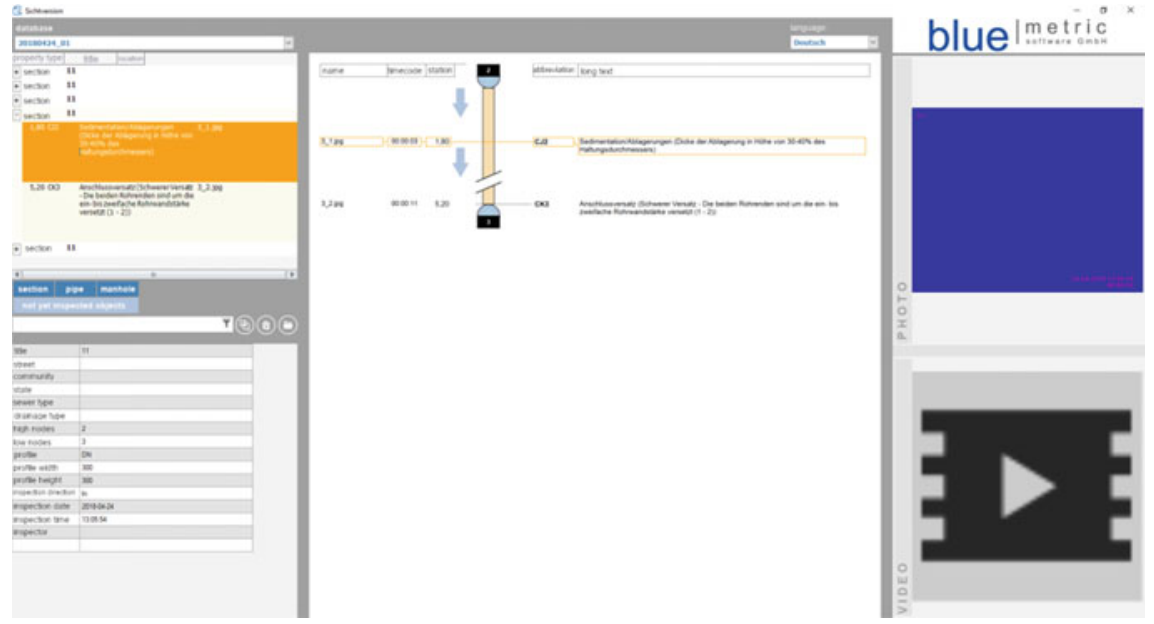

Fig. 7.24 Display programme
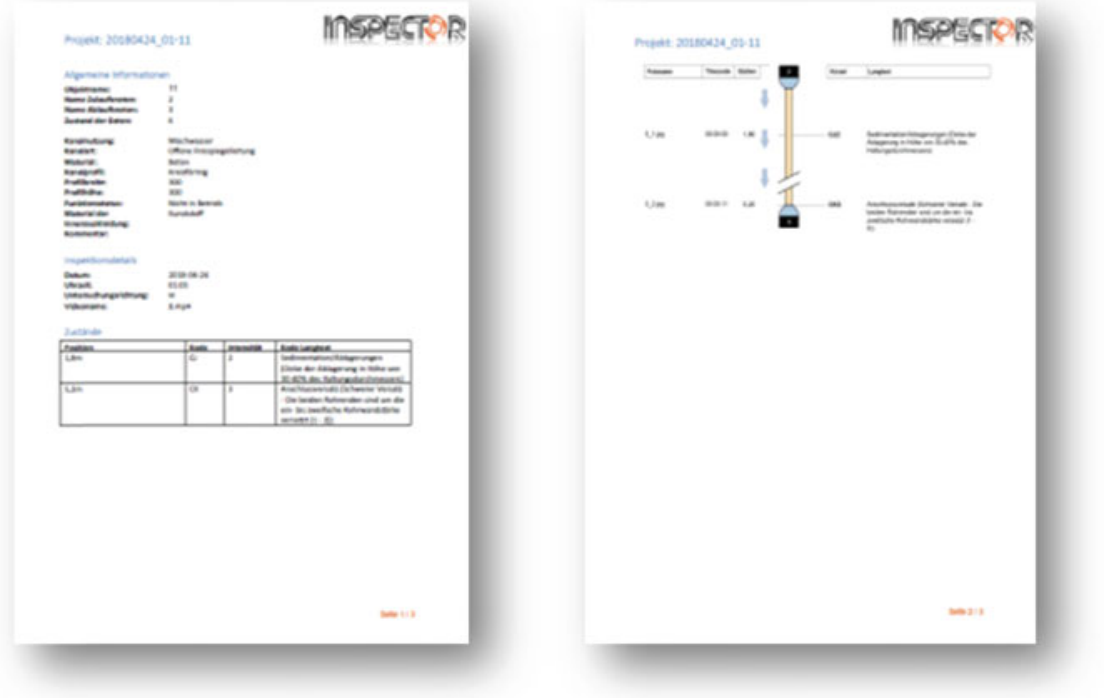

Fig. 7.25 Documented condition codes in tabular (left) and graphical form (right)

\subsubsection{First Demonstration of the Inspection Procedure}

In the scope of the first practical test in October 2017, bluemetric made a presentation for the project partners in Jiaxing, which served to illustrate the programme structure and the backgrounds. The experience gained with the standards-based condition 
recording in Germany was used to establish a connection to the set-up of the software for the practical test in China. Accordingly, the content was the programme flow of the software developed for this project and the structure of the condition codes used on the basis of the DWA, since the project partners initially had no specifications in this regard. In addition, the touch-based operating concept of the program was explained in detail so that the project partners could gain an insight into the handling of the software.

In the course of the first practical test in Jiaxing, the complete system was set up after unpacking the hardware and software. The commissioning was then carried out together with the Chinese skilled workers to explain the procedures of a condition recording with the software and hardware. The hardware components of JT elektronik $\mathrm{GmbH}$ were connected to the Chinese flushing vehicle and software adjustments were made to correctly connect the hardware.

Subsequently, a test run with the inspection sledge vehicle of JT elektronik GmbH took place in front of the premises of the Chinese partner company.

Following the practical tests, the findings were conclusively exchanged and feedback was given by the project partners on useful adaptions for further practical use.

\subsubsection{First Assessment of Process}

After completion of the first practical test in China, the on-site findings were analysed and the further procedure was determined. It was determined that due to the practical conditions on site - in contrast to Germany - flooded sewers are to be expected as a rule, since the sewers cannot be shoved clear at short notice for condition recording due to administrative reasons. Therefore it was decided that instead of a sledge, which mainly works in half-filled, a raft construction should be used.

Also on the software side, adaptations for the next practical test have been worked out. The data generated from the first practical test was viewed and the export was adjusted accordingly. Graphic elements were inserted into the report of the sewer section and further data were added. Furthermore, the master data of the main sewer objects and the condition standard of the software were extended by condition codes in accordance with the specifications of the Chinese project partners.

The software itself and its operating concept was very positively received by the Chinese project partners, so that no fundamental reconstruction works were necessary.

\subsubsection{Second Demonstration of the Inspection Procedure}

For the second practical test in April/ May 2018, the findings and suggestions from the first demonstration were implemented. With regard to the on-site demonstration, 


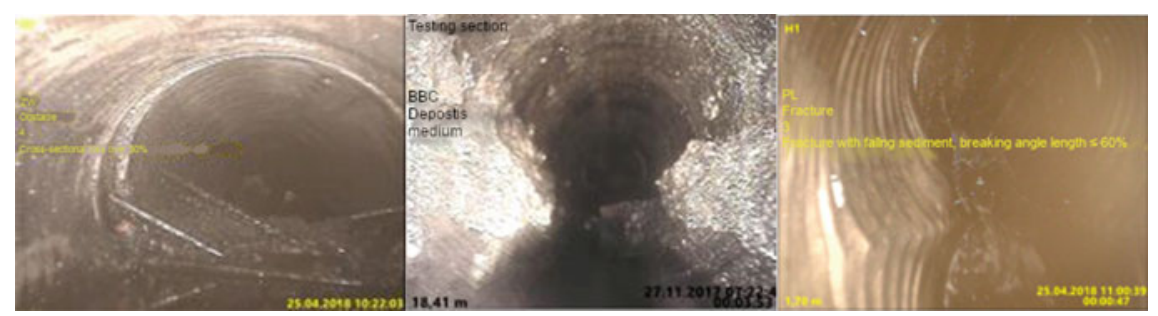

Fig. 7.26 Results of inspection (bluemetric)

the localisation (German, English and Mandarin) was implemented as far as possible and the inspection functions were programmed with the provided hardware.

The Chinese standard provided by our project partner FiW could be implemented for the condition documentation. This standard replaced the simplified condition recording, which was shown during the first demonstration. Since no formats for data transfer of the sewers to be inspected could be provided, the software was extended in such a way that the generation of sewer sections with corresponding master data is possible directly on site. A project management allows the temporal grouping of the work. As no exchange interface could be named during the analysis of the existing systems in China (in Germany a defined XML file is used for this purpose, DWA M150 or ISYBAU), it was decided to display the data via CSV file. In addition, a report with master data, sewer section graphics and the generated images per condition is available for each sewer section as a PDF file. Video files and image files have also been provided. In addition, a license-free "viewing version" was integrated for viewing the data. This enables the precise time-controlled navigation of the documented conditions in the video. Photos and reports on the inspected object can also be opened. No additional software is necessary to view the results of the sewer section inspection. The viewer can be started directly from a CD or USB drive. The resulting export files were successfully presented and have attracted great interest. The sewer sections inspected during the on-site demonstration showed enormous damage. The documented obstacles and deformations could be directly identified as the cause for the very high water level (Fig. 7.26).

In addition to the sewer sections in a residential area, a sewer section in an industrial area was also investigated. Here the raft construction created by JT-elektronik was used.

After on-site demonstration, the project was presented 2018 at the IEexpo in Shanghai. For this purpose, an imagine-film was commissioned, which shows the problems of wastewater disposal and introduces the involved companies.

\subsubsection{Second Assessment of Procedure}

As already experienced during the first practical test, the examined sewer sections showed very high water levels and deposits, so that an optical inspection was hardly 
feasible. However, the documentation produced was able to give those responsible a direct illustration of the problem. The documentation software was used successfully and, despite adverse conditions, recorded the condition of the sewers very clearly.

The presented technology can thus be applied to document the condition and causes of acute and flow-preventing objects by means of conditions, photos, video and position that can be electronically evaluated by machine. This can be used to plan measures. However, a comprehensive documentation of the condition is not possible due to the water level and the lack of cleaning. Rather, an initial documentation can be carried out so that critical problems can be localised and appropriate immediate measures can be taken to ensure that the wastewater is drained off. The crucial task of sewer cleaning in order to maintain the desired condition and remove contamination and deposits must be preceded by an inspection. The inspection for assessment and evaluation can only be carried out comprehensively in this way.

\subsection{Recommendations for Actions}

(See Tables 7.3, 7.4 and 7.5).

\section{Operational planning}

Table 7.3 Evaluation of the deposit situation

\begin{tabular}{|c|c|c|}
\hline $\begin{array}{l}\text { Task of Oper- } \\
\text { ation }\end{array}$ & Goals/ Recommendations for Action & Tools \\
\hline Data recording & $\begin{array}{l}\text { Assignment of deposition data accord- } \\
\text { ing to shaft and sewer section } \\
\text { - Digital data recording }\end{array}$ & $\begin{array}{l}\text { - TV-inspection } \\
\text { - Sewer data base / } \\
\text { KIS } \\
\text { - Standardised } \\
\text { protocols } \\
\text { - Mobile recording } \\
\text { devices }\end{array}$ \\
\hline Data editing & $\begin{array}{l}\text { - Evaluation according to drainage sys- } \\
\text { tems and pollution classes } \\
\text { - Visualising the data (Photo/ Video) }\end{array}$ & $\begin{array}{l}\text { - } \text { Sewer database/ KIS } \\
\text { - } \quad \text { GIS-systems }\end{array}$ \\
\hline Assessment & - Set-up of a Demand plan for cleaning & $\begin{array}{l}\text { - Assessment by } \\
\text { - Demand plan for } \\
\text { cleaning } \\
\text { - Visualisation/ GIS }\end{array}$ \\
\hline
\end{tabular}


Table 7.4 Assessment of the situation

\begin{tabular}{|c|c|c|}
\hline Operational Task & $\begin{array}{l}\text { Goals/ Recommendations for } \\
\text { Action }\end{array}$ & Tools \\
\hline Data recording & $\begin{array}{l}\text { - Manhole and section of } \\
\text { sewer-related assignment } \\
\text { of the damage situation } \\
\text { - Digital data recording }\end{array}$ & $\begin{array}{l}\text { - TV-inspection } \\
\text { - Sewer database/ KIS } \\
\text { - Standardized protocols } \\
\text { - Mobile recording } \\
\text { devices }\end{array}$ \\
\hline Data editing & $\begin{array}{l}\text { - Evaluation according to } \\
\text { specified standards for } \\
\text { condition } \\
\text { - Visualisation of the date } \\
\text { (photo/ video) }\end{array}$ & $\begin{array}{l}\text { - Sewer data-base/ KIS } \\
\text { - Creation of a data ex- } \\
\text { change interface } \\
\text { - Training of specialists } \\
\text { - Engineer assessment }\end{array}$ \\
\hline Assessment & $\begin{array}{l}\text { - Establishment of an in- } \\
\text { spection plan } \\
\text { - Priority determination }\end{array}$ & $\begin{array}{l}\text { - Engineer assessment } \\
\text { - Inspection plan } \\
\text { - Visualisation/ GIS }\end{array}$ \\
\hline
\end{tabular}

Table 7.5 Operational planning

\begin{tabular}{|c|c|c|}
\hline Operational Task & Goals/ Recommendations for Action & Tools \\
\hline $\begin{array}{l}\text { Organisation and } \\
\text { relevance }\end{array}$ & $\begin{array}{l}\text { - Organisation of a fast availability } \\
\text { of capacities to eliminate inci- } \\
\text { dents } \\
\text { - Planning of the daily/ weekly } \\
\text { cleaning and inspection opera- } \\
\text { tions }\end{array}$ & $\begin{array}{l}\text { - Flushing and opera- } \\
\text { tion plan }\end{array}$ \\
\hline Service and costs & $\begin{array}{l}\text { - Generation of performance re- } \\
\text { ports on cleaned manholes and } \\
\text { sewers } \\
\text { - Recording of operating costs } \\
\text { - Identification of the need for re- } \\
\text { habilitation and a rehabilitation } \\
\text { strategy }\end{array}$ & $\begin{array}{l}\text { - Sewer data-base / } \\
\text { KIS } \\
\text { - Daily reports } \\
\text { - Mobile data record- } \\
\text { ing } \\
\text { - Statistical surveys }\end{array}$ \\
\hline
\end{tabular}




\section{References}

1. Deutsches Institut für Normung (2017) DIN - kurz erklärt. https://www.din.de/de/ueber-nor men-und-standards/basiswissen, zuletzt abgerufen am 15 July 2017

2. DIN 1986-3 (2004) Entwässerungsanlagen für Gebäude und Grundstücke - Teil 3: Regeln für Betrieb und Wartung. Beuth Verlag GmbH, Berlin

3. DIN EN 13508-2 (2011) Untersuchung und Beurteilung von Entwässerungssystemen außerhalb von Gebäuden - Teil 2: Kodiersystem für die optische Inspektion. Beuth Verlag GmbH, Berlin

4. DIN EN 752-5 (1997) Entwässerungssysteme außerhalb von Gebäuden - Teil 5: Sanierung; Deutsche Fassung EN 752-5:1997. Beuth Verlag GmbH, Berlin

5. DWA-M 149-5 (2010) Zustandserfassung und -beurteilung von Entwässerungssystemen außerhalb von Gebäuden - Teil 5: Optische Inspektion. Hennef: DWA.

6. DWA-M 150 (2010) Datenaustauschformat für die Zustandserfassung von Entwässerungssystemen (April 2010). DWA, Hennef

7. Lecher K, Lühr H-P, Zanke UCE (eds) (2001) Taschenbuch der Wasserwirtschaft. Springer Vieweg, Wiesbaden

8. (LfU) Bayerisches Landesamt für Umwelt (Hrsg.) (2016) Leitfaden zur Inspektion und Sanierung kommunaler Abwasserkanäle. LfU, Augsburg

9. Meteoblue (2016) Klima Modell Jiaxing. https://www.meteoblue.com/de/wetter/historycl imate/climatemodelled/jiaxing_china_1805953, zuletzt abgerufen am 15 July 2017

10. STATISTA (2013) Länge des Kanalnetzes in Deutschland. http://de.statista.com/statistik/daten/ studie/152743/umfrage/laenge-deskanalnetzes-in-deutschland-im-jahr-2007/

11. Guo S, Shao Y, Zhang T, Zhu DZ, Zhang Y (2013) Physical modeling on sand erosion around defective sewer pipes under the influence of groundwater. J. Hydra. Eng. 139(12):1247-1257

12. Zhou Y, Zhang Y, Tang P, Chen Y, Zhu DZ (2013) Experimental study of the performance of a siphon sediment cleansing set in a CSO chamber. Water Sci Technol 68(1): 184-191.

13. Guo S, Zhang T, Zhang Y, Zhu DZ (2013) An approximate solution for two-dimensional groundwater infiltration in sewer systems. Water Sci Technol 67(2):347-352

14. Zhou Y, Zhang Y, Tang P (2013) Field performance of self-siphon sediment cleansing set for sediment removal in deep CSO chamber. Water Sci Technol 67(2):278-283

Open Access This chapter is licensed under the terms of the Creative Commons Attribution 4.0 International License (http://creativecommons.org/licenses/by/4.0/), which permits use, sharing, adaptation, distribution and reproduction in any medium or format, as long as you give appropriate credit to the original author(s) and the source, provide a link to the Creative Commons license and indicate if changes were made.

The images or other third party material in this chapter are included in the chapter's Creative Commons license, unless indicated otherwise in a credit line to the material. If material is not included in the chapter's Creative Commons license and your intended use is not permitted by statutory regulation or exceeds the permitted use, you will need to obtain permission directly from the copyright holder.

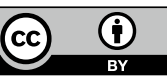

